\title{
Caracterización epidemiológica de la infección por VIH/SIDA en Chile. Diciembre de 2003
}

\author{
COMISIÓN NACIONAL DE SIDA-CONASIDA
}

\section{Epidemiology of HIV/AIDS in Chile. December 2003}

From 1984, when the first case of AIDS was diagnosed in Chile, to December 2003, 6.060 patients with AIDS and 6.514 with asymptomatic HIV infection have been notified to a passive national surveillance system; around 3,800 have died due to the infection. Magnitude of the under reporting is discussed. Assumed routes of the infection have been: sexual (94.1\%), blood- largely intravenous drug use- $(4.3 \%)$ and vertical transmission $(1.6 \%)$. According to analysis performed by the National Commission on AIDS (CONASIDA), a governmental office, HIV/AIDS epidemic in Chile is characterized by: predominance in male homo/bisexuals, urban and rural distribution, impoverishment of the affected people, diagnosis made mainly during adulthood and a steady trend to affecting more women and heterosexuals at large. Since 2001 there has been a continuous increase in access to standard antiretroviral therapy (HAART) for those cared for by the public health system, reaching free coverage for $100 \%$ of this population by 2003 , which has determined a significant decrease in the rate AIDSassociated clinical manifestations while reaching an stop of the previously increasing lethality of the infection (from a 15\% increase from 1993-1997 to 0.2\% from 1998-2003)

Key words: Human immunodeficiency virus; AIDS; Epidemiology; Chile.

Palabras claves: Virus de inmunodeficiencia humana; SIDA; Epidemiología; Chile.

Las estimaciones del Programa Conjunto de Naciones Unidas para la infección por VIH/SIDA (ONUSIDA), muestran que hasta fines del 2003 había en el mundo un total de 40 millones de personas afectadas por infección por VIH/SIDA, con un rango que va desde 34 a 46 millones, de los cuales 37 millones correspondían a adultos y 2,5 millones a niños y jóvenes bajo 15 años. Las defunciones fueron 3,0 millones correspondiendo 2,5 millones a adultos y 500.000 a niños y jóvenes bajo 15 años (Tabla 1). Se calcula que durante el año 2003 un total de 5 millones de personas adquirieron la infección en el mundo: 4,2 millones adultos y 700.000 niños y jóvenes bajo 15 años de edad ${ }^{1}$.

En un panorama mundial, en gran parte de África sub-sahariana la prevalencia del VIH permanece establemente elevada. Es decir, persisten niveles altos de nuevas adquisiciones del virus las cuales se juntan con elevadas cifras de mortalidad por SIDA. Además de la epidemia de África sub-sahariana, otras epidemias más recientes continúan creciendo, es así en China, Papúa Nueva Guinea, Vietnam, algunas repúblicas de Asia Central, los estados Bálticos y África del Norte (Tabla 2).

En América Latina y El Caribe se estiman actualmente en más de 2 millones las personas con infección por VIH/SIDA, incluidas las 200.000 que adquirieron la infección durante el año 2002. A lo menos 100.000 personas fallecieron de SIDA en este período, siendo un número muy elevado que ubica a la zona después de África sub-sahariana y Asia.

La epidemia en la región cuenta con 12 países en los que la prevalencia es a lo menos $1 \%$. La principal modalidad de transmisión en Latinoamérica sigue siendo por relaciones sexuales en-

La información sobre la epidemia y los distintos números del Boletín Epidemiológico del VIH/SIDA en Chile, además de otros documentos relacionados, se encontraran disponibles en el sitio www.minsal.cl/iniciativas/Conasida/conasida.htm o www.conasida.cl

Recibido: 20 diciembre 2004

Aceptado: 20 enero 2005 
tre hombres, seguida por las prácticas asociadas al uso de drogas inyectables, apreciándose desde los años 90 un incremento de la transmisión heterosexual. Lo anterior parece desempeñar un rol importante en la feminización de la epidemia, puesto que algunas investigaciones demuestran que una proporción importante de hombres que tiene relaciones sexuales con hombres (HSH) también tienen relaciones sexuales con mujeres.
Un estudio en siete países de América Central en HSH encontró prevalencias de infección por VIH entre 8 y $18 \%$. Otro estudio reciente realizado en Honduras en población de HSH encontró una prevalencia de infección por VIH de $13 \%$ junto a un reducido uso de preservativo, gran número de parejas sexuales y baja percepción del riesgo ${ }^{2}$.

Sin embargo, existe gran variabilidad del patrón de transmisión al interior de la región. Un

Tabla 1. Resumen mundial de la epidemia de infección por VIH/SIDA. Diciembre 2003

\section{Personas infectadas con VIH/SIDA:}

Total:

Adultos:

Niños y jóvenes bajo 15 años:

Nuevas infecciones por VIH en 2003:

Total:

Adultos:

Niños y jóvenes bajo 15 años:

$$
\begin{array}{ll}
40,0 \text { millones } & (34-46 \text { millones }) \\
37,0 \text { millones } & (31-43 \text { millones }) \\
2,5 \text { millones } & (2,1-2,9 \text { millones })
\end{array}
$$

$\begin{array}{ll}5,0 \text { millones } & (4,2-5,8 \text { millones }) \\ 4,2 \text { millones } & (3,6-4,8 \text { millones }) \\ 700.000 & (590.000-810.000)\end{array}$

Defunciones por SIDA durante 2003:

Total:

3,0 millones

(2,5-3,5 millones)

Adultos:

2,5 millones

(2,1 - 2,9 millones)

Niños y jóvenes bajo 15 años:
$(420.000-580.000)$

\begin{tabular}{|c|c|c|c|c|}
\hline Región & $\begin{array}{l}\text { Adultos y niños } \\
\text { con infección por } \\
\text { VIH/SIDA }\end{array}$ & $\begin{array}{l}\text { Adultos y niños } \\
\text { que adquirieron el } \\
\text { virus en año } 2003\end{array}$ & $\begin{array}{c}\text { Prevalencia } \\
\text { entre adultos } \\
\%\end{array}$ & $\begin{array}{l}\text { Defunción de } \\
\text { adultos y niños por } \\
\text { SIDA, año } 2003\end{array}$ \\
\hline África sub-sahariana & 25,0 - 28,2 millones & $3,0-3,4$ millones & $7,5-8,5$ & $2,2-2,4$ millones \\
\hline $\begin{array}{l}\text { África del Norte y } \\
\text { Oriente Medio }\end{array}$ & $470.000-730.000$ & $43,000-67,000$ & $0,2-0,4$ & $35,000-50,000$ \\
\hline $\begin{array}{l}\text { Asia meridional y } \\
\text { sudoriental }\end{array}$ & 4,6 - 8,2 millones & $610.000-1,1$ millones & $0,4-0,8$ & $330.000-590.000$ \\
\hline $\begin{array}{l}\text { Asia Oriental y } \\
\text { Pacífico }\end{array}$ & 700.000 - 1,3 millones & $150.000-270.000$ & 0,1 & $32.000-58.000$ \\
\hline América Latina & 1,3 - 1,9 millones & $120.000-180.000 \mathrm{mil}$ & $0,5-0,7$ & $49.000-70.000$ \\
\hline Caribe & $350.000-590.000$ & $45.000-80.000$ & $1,9-3,1$ & $30.000-50.000$ \\
\hline $\begin{array}{l}\text { Europa oriental y } \\
\text { Asia central }\end{array}$ & $1,2-1,8$ millones & $180.000-280.000 \mathrm{mil}$ & $0,5-0,9$ & $23.000-37.000$ \\
\hline Europa occidental & $520.000-680.000$ & $30.000-40.000$ & 0,3 & $2.600-3.400$ \\
\hline América del Norte & 790.000 - 1,2 millones & $36.000-54.000$ & $0,5-0,7$ & $12.000-18.000$ \\
\hline $\begin{array}{l}\text { Australia y Nueva } \\
\text { Zelandia }\end{array}$ & $12.000-18.000$ & $700-1.000$ & 0,1 & $<100$ \\
\hline Total & 40 millones & 5 millones & $1,1 \%$ & 3 millones \\
\hline
\end{tabular}

Fuente: ONUSIDA 2003

Tabla 2. Estadísticas y características regionales de la infección por VIH/SIDA. Diciembre 2003

Fuente: ONUSIDA 2003. 
ejemplo de esto es el caso de Argentina, donde la categoría de exposición mayoritaria es a través de compartir jeringas durante la práctica de uso de drogas inyectables ${ }^{3}$. Así, 40\% de los nuevos casos notificados en ese país corresponde a casos transmitidos por prácticas asociadas al uso de drogas intravenosas ${ }^{1}$. Para varios países de la zona constituye una preocupación la relación entre drogas e infección por VIH, en el entendido que el consumo de drogas por cualquier vía favorece conductas de riesgo.

La relación entre hombres y mujeres con infección por VIH se ha estrechado en el tiempo, llegando hasta 3 hombres por cada mujer en América Latina y 2 hombres por cada mujer en El Caribe, confirmando que existe una tendencia a la feminización de la epidemia.

América Latina y El Caribe presentan factores que favorecen la propagación del VIH dentro de los cuales destacan las desigualdades e inequidades socioeconómicas y de género junto a la movilidad de la población. Afortunadamente, cada vez es más evidente la determinación de los diferentes países por enfrentar y frenar la epidemia de infección por VIH/SIDA. Es así como los Gobiernos, el Sistema de Naciones Unidas y la sociedad civil se han propuesto trabajar en conjunto para canalizar recursos desde el Fondo Mundial para la Lucha contra el SIDA, la Tuberculosis y la Malaria. Este aporte apunta a disminuir el impacto de la epidemia, incluyendo los esfuerzos por proporcionar terapia anti-retroviral (TARV). El Fondo cuenta con más de 4.700 millones de dólares en promesas de contribuciones y ha aportado fondos a 93 países, uno de los cuales es Chile.
Este financiamiento contribuirá a dar cumplimiento a los Compromisos Declarados por los Estados Miembros de las Naciones Unidas en el 2001, donde se fijaron metas específicas con plazos determinados en la lucha contra la infección por VIH/SIDA (compromisos adquiridos por los países en la Asamblea General Extraordinaria de Naciones Unidas).

En nuestro país la vigilancia epidemiológica de la infección por VIH/SIDA se realiza fundamentalmente por mecanismo pasivo, por notificación obligatoria de los casos de SIDA (de acuerdo a la definición del CDC 1987) y personas infectadas por VIH asintomáticas (portadoras) diagnosticadas en el país. También se realizan eventuales estudios de seroprevalencia de VIH, que corresponde al mecanismo activo de la vigilancia. El análisis de la información generada por el sistema de vigilancia pasiva permite caracterizar la epidemia de infección por VIH/SIDA en Chile y se muestra en los siguientes datos.

La sensibilidad del sistema de vigilancia pasiva de SIDA, es decir, la probabilidad de que un caso sea notificado, de acuerdo al proceso de revisión de los certificados de defunción iniciado en 1991, se estimó en $75 \%$ en 2003, es decir, la subnotificación alcanzó a 25,0\% no existiendo patrones de comparación con otras patologías. Se ha producido un aumento respecto al año anterior, ya que el 2002 se encontró una sensibilidad del sistema de $72,5 \%$ con una subnotificación de $27,5 \%$ (Gráfico 1). Los cambios podrían ser explicados por mejorías en el registro de las causas de muerte en los certificados médicos de defunción* producto de la disminución de la

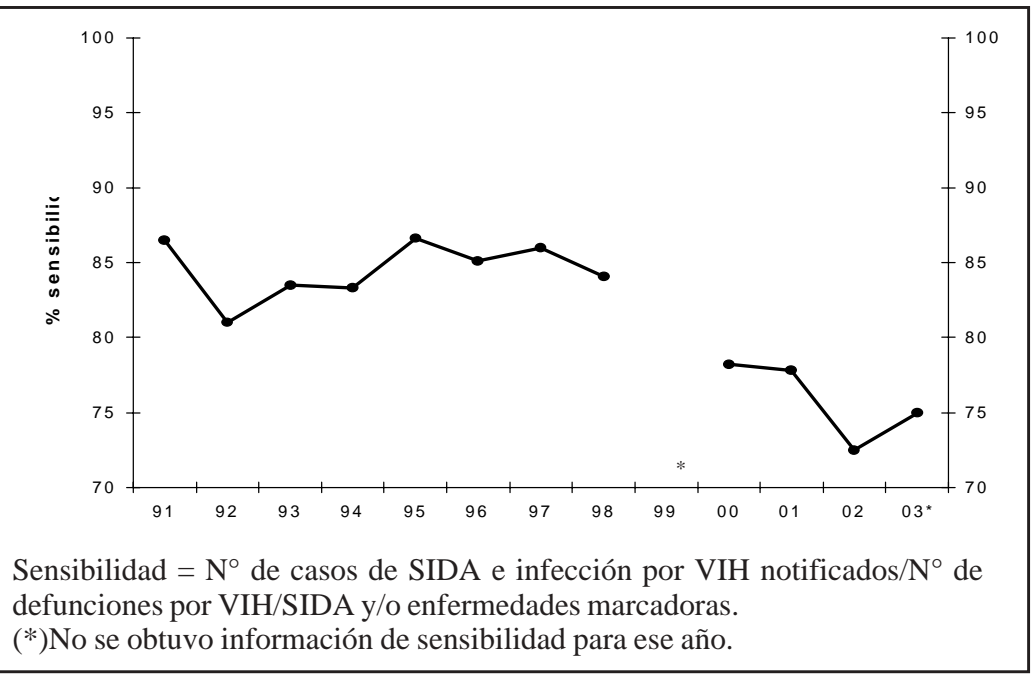

Gráfico 1. Sensibilidad de la notificación de casos de SIDA e infección por VIH. Chile, 1991-2003.

* Comunicación personal obtenida del Comité Científico Asesor. Santiago. Octubre 2003. 
estigmatización de los afectados y mejorías en Estadísticas del Ministerio de Salud (MINSAL).

La mortalidad aumentó hasta el año 1997, con un descenso que se mantuvo hasta el 2000 por la incorporación de la biterapia. El impacto de la expansión del acceso a TARV se describió en el documento técnico del Boletín Epidemiológico $\mathrm{N}^{\circ} 14$ de CONASIDA.

Es necesario aclarar que los certificados de defunción no constituyen notificación de nuevos casos, como ocurre en otros países de la región. La revisión se hace para conocer el número de personas que fallecen a causa de la infección por VIH/SIDA y verificar si habían sido notificados, para dimensionar la subnotificación, corregir la tasa de mortalidad y proyectar las tendencias.

La evaluación del sistema de vigilancia demuestra que existe un período de latencia de la notificación, por lo que las cifras que se exhiben en este documento correspondiente al año 2003 son preliminares.

\section{Casos de SIDA e infección por VIH}

El primer caso de SIDA en nuestro país fue notificado en 1984; hasta el 31 de diciembre de 2003 se habían notificado 6.060 enfermos y 6.514* personas infectadas por VIH asintomáticas en las trece regiones del país. Se había informado el fallecimiento por SIDA de 3.860 personas y un total de 214 fallecidos con infección por VIH.

La tasa de incidencia anual de SIDA muestra una tendencia al aumento a través de los años hasta 1998, en que se observa un descenso de $12,0 \%$ respecto a 1997 , lo que puede atribuirse al impacto de la biterapia implementada a partir de 1997. Como ha sido demostrado en experiencias internacionales, la biterapia evita la aparición de enfermedades marcadoras y por lo tanto el avance de la enfermedad a SIDA, pero este efecto sería transitorio. La tendencia cambió a partir de 1997, quebrándose, con fluctuaciones que pueden atribuirse al impacto inicial de la biterapia y luego al inicio de la triterapia, pudiendo asumirse que el impacto de la expansión del acceso a TARV del 2001-2003 se evidenciará en los años siguientes, considerando que la infección por VIH/SIDA tiene $100 \%$ de cobertura para gastos médicos desde 2003 al ser una patología incluida en el Plan de Acceso Universal a Garantías Explícitas (AUGE). Al analizar ambas curvas en forma paralela, VIH y SIDA, se puede observar una brecha que años anteriores no se apreciaba, particularmente para el año 2002, debido al crecimiento de la incidencia de infección por VIH en comparación con el decrecimiento de la incidencia de SIDA, la cual puede ser atribuida al aumento de acceso a TARV (Gráfico 2).

\section{Estimaciones}

Se han desarrollado diversas metodologías en el mundo para estimar el número real de personas afectadas por VIH/SIDA. En el caso de Chile se muestran distintos análisis que permiten tener una aproximación al número de casos de SIDA e

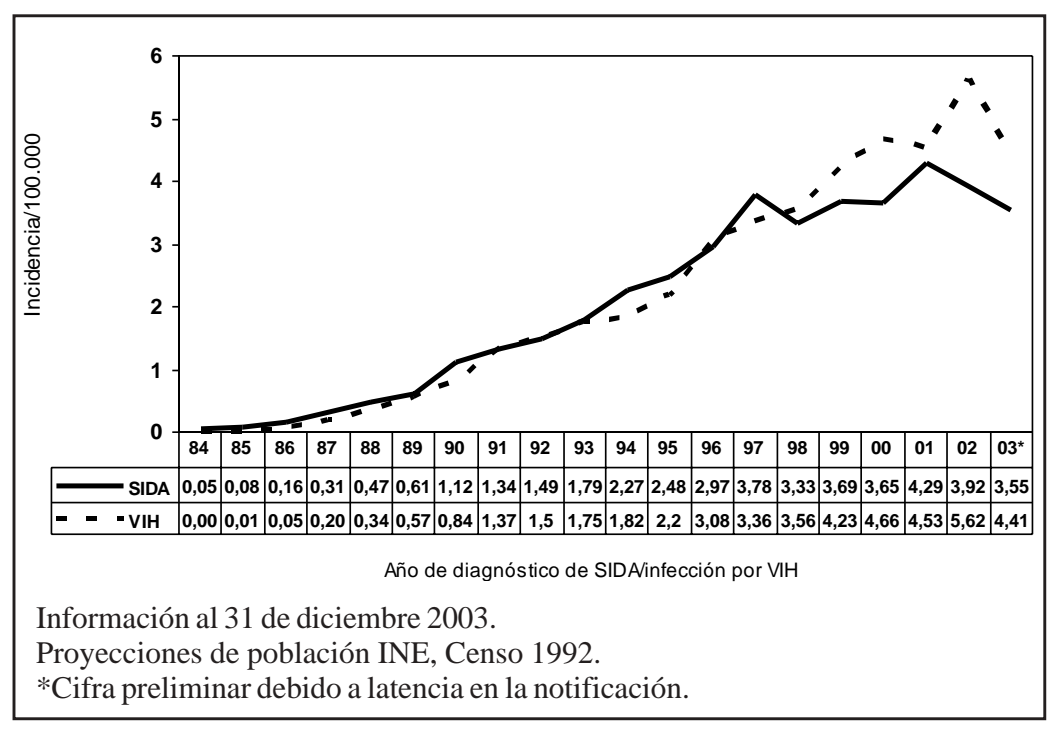

Gráfico 2. Incidencia de SIDA e infeccion por VIH por año de diagnóstico. Chile, 1984-2003. Se refiere al número de personas asintomáticas viviendo con VIH notificadas, y no refleja necesariamente la situación real de la infección por VIH. 
infección por VIH totales, muertes y personas con infección por VIH/SIDA.

\section{Notificaciones de la infección por VIH/SIDA en Chile}

\section{Casos de SIDA e infección por VIH notificados}

A través del sistema de vigilancia epidemiológica pasiva, que en Chile incluye los casos de SIDA y la infección por VIH, al 31 de diciembre del 2003 se habían notificado 6.060 casos de SIDA y 6.514 casos de infección por VIH.

\section{Casos de SIDA fallecidos notificados}

A la misma fecha se había recibido la notificación de la defunción por SIDA de 3.860 personas.

Estimaciones de la infección por VIH/SIDA en Chile basadas en la notificación de casos de SIDA

\section{Corrección de casos de SIDA por subnotificación}

A través de la revisión de certificados de defunción se estima la subnotificación, que en la revisión de 2003 alcanzó a 25,0\%. Este porcentaje equivale 2.020 casos no notificados acumulados, los que sumados a los 6.060 casos de SIDA notificados al 31 de diciembre del 2003 permiten estimar en 8.080 los casos de SIDA.

\section{Estimación de personas infectadas con VIH asintomáticas}

Para estimar las personas infectadas por VIH se multiplica cada caso de SIDA por 3,76 empleando el resultado obtenido para Chile mediante el método de retrocálculo en la publicación: "Situación epidemiológica y económica del SIDA en América Latina y el Caribe", SIDALAC, 1998, similar al obtenido en Chile por Villarroel $\mathrm{L}^{5}$.

Con este cálculo se estiman en $\mathbf{3 0 . 3 8 1}$ las personas infectadas con VIH a la fecha indicada.

\section{Estimación de casos con SIDA \\ e infección por VIH asintomática}

Los casos de SIDA estimados luego de corregida la subnotificación (8.080), se suman a las personas con infección por VIH estimadas (30.381), obteniéndose $\mathbf{3 8 . 4 6 1}$ personas estimadas con infección por VIH/SIDA acumuladas desde 1984 hasta el 31 de diciembre del 2003, considerando vivos y fallecidos.

\section{Estimación de casos con SIDA fallecidos}

Para estimar el número real de personas fallecidas por SIDA, a los 3.860 casos de SIDA fallecidos notificados se aplica la corrección por subnotificación $(25,0 \%)$, equivale a 1.287 defunciones subnotificadas, se estiman las muertes por SIDA a la mencionada fecha en 5.147 .

\section{Estimación de casos de SIDA y personas infec- tadas por VIH vivas}

Para estimar el número de personas vivas con infección por VIH/SIDA, se deducen las muertes estimadas, corregidas por subnotificación, (5.147), del total de casos de infección por VIH/ SIDA acumulados corregidos por subnotificación, (38.461), entregando una cifra de $\mathbf{3 3 . 3 1 4}$ personas infectadas con VIH/SIDA al 31 de diciembre del 2003.

Estimación ONUSIDA de casos de SIDA y personas infectadas con VIH basada en el número de personas que requieren tratamiento

Como una forma de operacional de efectuar proyecciones desde la demanda se estima que alrededor de $15 \%$ del total de personas infectadas con VIH requieren tratamiento. En el Sistema Nacional de Servicios de Salud, a julio del 2004, 4.838 personas están en tratamiento, por lo que el número de personas infectadas con VIH vivas correspondientes sería de 27.415. Si se calcula que las personas que corresponden al sector público de Salud son el $83 \%$ de la población, entonces en el privado existirían 6.606 personas $(17 \%)$, por lo que el total de personas infectadas con VIH sería de $\mathbf{3 8 . 8 5 9}$.

\section{Estimación de infecciones nuevas por día}

Si se producen aproximadamente 573 casos de SIDA nuevos al año (promedio anual entre 1998 y 2002), se estima que se infectan 2.154 personas al año, es decir, $\mathbf{5 , 9}$ personas/día.

\section{Distribución geográfica de los casos de SIDA}

Chile está organizado y dividido desde el punto de vista político-administrativo en trece regiones, las cuales se subdividen en provincias y estas, a su vez, en comunas.

De acuerdo a la región de ocurrencia de los casos (lugar donde se atendieron la primera vez que fueron notificados), las tasas de incidencia 
acumuladas 1984-2003/100.000 habitantes sobre el promedio nacional corresponden a: Región Metropolitana (70,5), I ${ }^{\mathrm{a}}$ Región de Tarapacá $(57,0), V^{\mathrm{a}}$ Región de Valparaíso $(56,6)$. La II ${ }^{\mathrm{a}}$ Región de Antofagasta está bajo el promedio $(38,7)$. La tasa de incidencia nacional de SIDA acumulada es 43,7/100.000 habitantes (Gráfico 3).

Al comparar las incidencias acumuladas regionales al 2003 con el corte de análisis anterior se registra el aumento de la I ${ }^{\mathrm{a}}$ Región, sobrepasando a la $\mathrm{V}^{\mathrm{a}}$ Región. También se produce un ascenso tanto de la IX ${ }^{\mathrm{a}}$ Región de la Araucanía, desde el lugar $11^{\circ}$ al $8^{\circ}$, como de la $\mathrm{X}^{\mathrm{a}}$ Región de Los Lagos, esta última desde el lugar $10^{\circ}$ a la $9^{\circ}$. A la vez se registra un descenso de la XII ${ }^{\mathrm{a}}$ Región de Magallanes desde el $9^{\circ}$ a $11^{\circ}$ y de la XI ${ }^{\mathrm{a}}$ Región de Aysén desde el puesto $8^{\circ}$ al $10^{\circ}$. La información de la tasas de incidencia acumulada/100.000 habitantes en el período 1984-2003 por Región se presentan en orden descendente en la Tabla 3.

\section{Tendencia anual de SIDA e infección por VIH en regiones seleccionadas}

En el Gráfico 4 se muestra una tendencia anual de SIDA en regiones seleccionadas por una mayor ocurrencia de casos en el período 19902003. La Región Metropolitana tiene tasas superiores al promedio nacional durante todo el período y la $V^{\text {a }}$ Región mantuvo igual condición hasta el año 1999 cuando se produjo una disminución en su tasa bajo el promedio nacional para, a partir del año 2000, registrar nuevamente un aumento sobre el nivel nacional. Desde el año 1999 la I $^{\mathrm{a}}$ Región sobrepasó tanto el promedio nacional como a la V ${ }^{a}$ Región, con una tasa de incidencia anual
2003 de 8,15 casos/100.000 habitantes. La II ${ }^{\mathrm{a}}$ Región sobrepasa el promedio nacional en el período 2000-2002 alcanzando una tasa de incidencia para el año 2003 de 2,88 casos SIDA/ 100.000 habitantes. El 2003 (información preliminar) está bajo el promedio nacional.

El Gráfico 5 muestra la tendencia anual de la infección por VIH en las regiones seleccionadas por presentar tasas más elevadas en el período 1990-2003. Entre los años 1999 y 2003 cuatro regiones superaron el promedio nacional destacando fuertemente la I ${ }^{\text {a }}$ Región a partir de 1999 donde se produjo una tasa de 8,91/100.000 habitantes, llegando el año 2002 a 14,10 casos/100.000 habitantes y cifras preliminares en el 2003 de 5,75 casos/100.000 habitantes. El promedio nacional para 1999 fue 4,23/100.000 habitantes y 4.46/ 100.000 habitantes en el 2003.

\section{Análisis por Servicios de Salud de ocurrencia}

El Sistema de Salud Público chileno cuenta con el Sistema Nacional de Servicios de Salud (SNSS) los cuales deben satisfacer las necesidades de salud de la población. Están ubicados de manera de facilitar el acceso al sistema de salud, pudiendo existir más de uno por Región. La Tabla 4 muestra los casos y tasas de incidencia acumulada de infección por VIH y SIDA por Servicio de Salud de ocurrencia, asignándose el caso al primer Servicio que lo notifica. Se detallan por separado en hombres y mujeres. Las atenciones se concentran en los Servicios de Salud de la Región Metropolitana y de la $\mathrm{V}^{\mathrm{a}}$ Región; sin embargo, también es notoria la tasa de los Servicios de Salud de las regiones I ${ }^{\mathrm{a}}, \mathrm{II}^{\mathrm{a}}$,

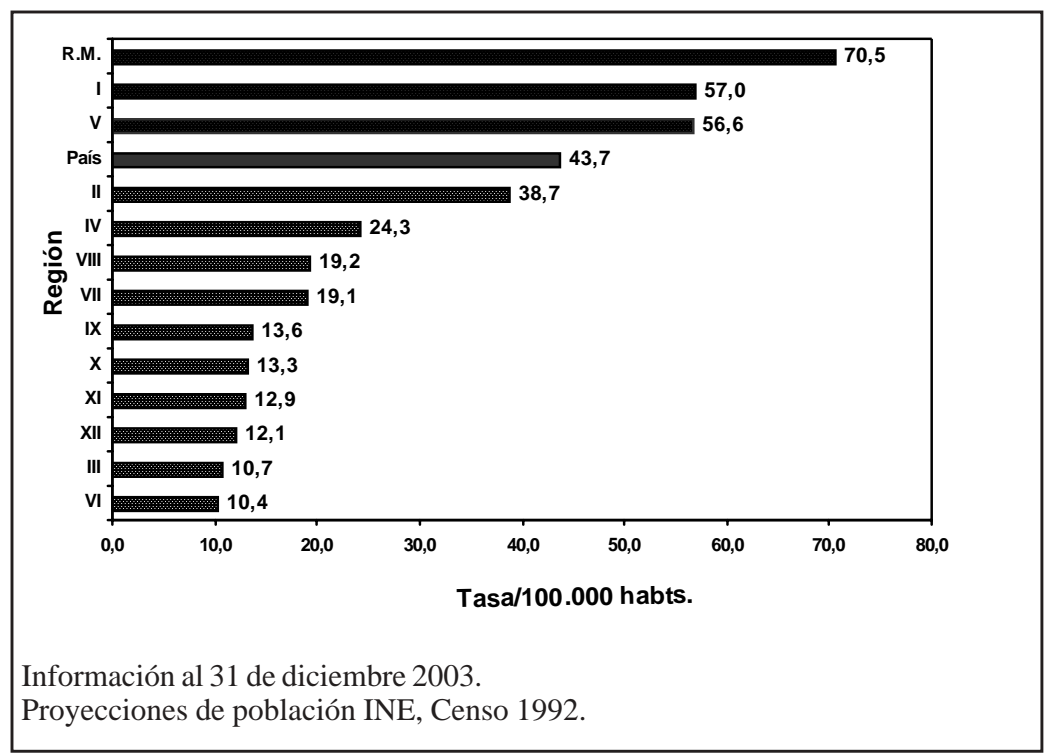

Gráfico 3. Incidencia acumulada de SIDA por Región de ocurrencia. Chile, 1984-2003. Cifra preliminar debido a latencia en la información. 
Tabla 3. Incidencia acumulada de SIDA por regiones. Chile. 1984-2003*

\begin{tabular}{|c|c|c|c|}
\hline Región & Servicios de Salud & Número de casos & $\begin{array}{c}\text { Tasa acumulada/100.000 } \\
\text { habitantes }\end{array}$ \\
\hline R.M & $\begin{array}{l}\text { M Norte } \\
\text { M Occidente } \\
\text { M Central } \\
\text { M Oriente } \\
\text { M Sur } \\
\text { M Sur Oriente }\end{array}$ & 3.471 & 70,5 \\
\hline I & $\begin{array}{l}\text { Arica } \\
\text { Iquique }\end{array}$ & 203 & 57,0 \\
\hline $\mathrm{V}$ & $\begin{array}{l}\text { Valparaíso/San Antonio } \\
\text { Viña del Mar/Quillota } \\
\text { Aconcagua }\end{array}$ & 814 & 56,6 \\
\hline II & Antofagasta & 165 & 38,7 \\
\hline IV & Coquimbo & 127 & 24,3 \\
\hline VIII & $\begin{array}{l}\text { Ñuble } \\
\text { Concepción/Arauco } \\
\text { Talcahuano } \\
\text { Bío-Bío }\end{array}$ & 345 & 19,2 \\
\hline VII & Maule & 164 & 19,1 \\
\hline IX & Araucanía (Norte y Sur) & 110 & 13,6 \\
\hline $\mathrm{X}$ & $\begin{array}{l}\text { Valdivia } \\
\text { Osorno } \\
\text { Llanchipal }\end{array}$ & 131 & 13,3 \\
\hline XI & Aysén & 11 & 12,9 \\
\hline XII & Magallanes & 18 & 12,1 \\
\hline III & Atacama & 26 & 10,7 \\
\hline VI & O`Higgins & 75 & 10,4 \\
\hline País & & 6.060 & 43,7 \\
\hline
\end{tabular}

* Datos preliminares a diciembre 2003 por latencia de la información. CONASIDA-MINSAL.

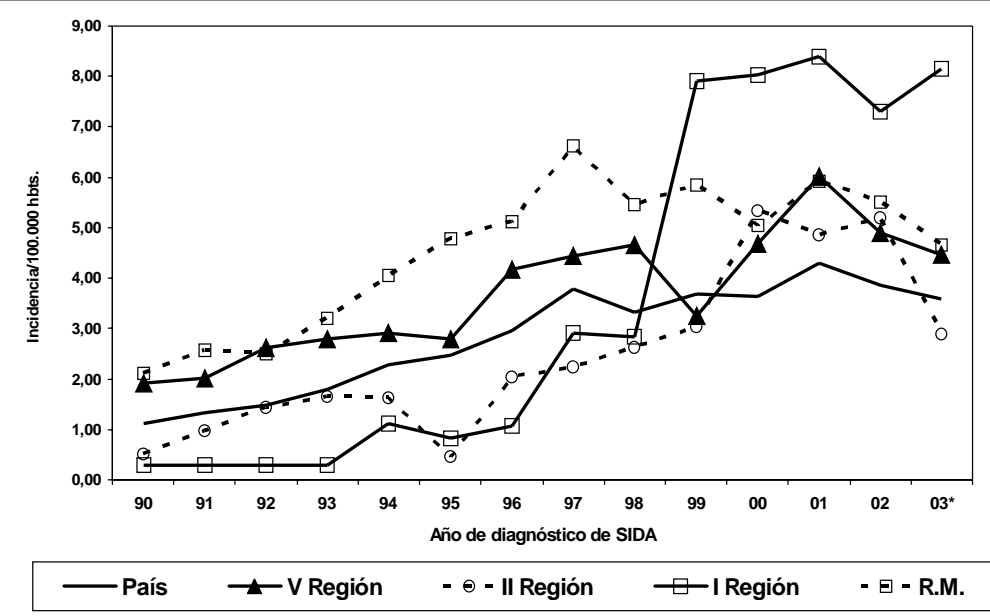

Información al 31 de diciembre 2003. Proyecciones de población INE, Censo 1992.
Gráfico 4. Incidencia anual de SIDA en regiones seleccionadas. Chile, 1990-2003. Cifra preliminar debido a latencia en la notificación. 


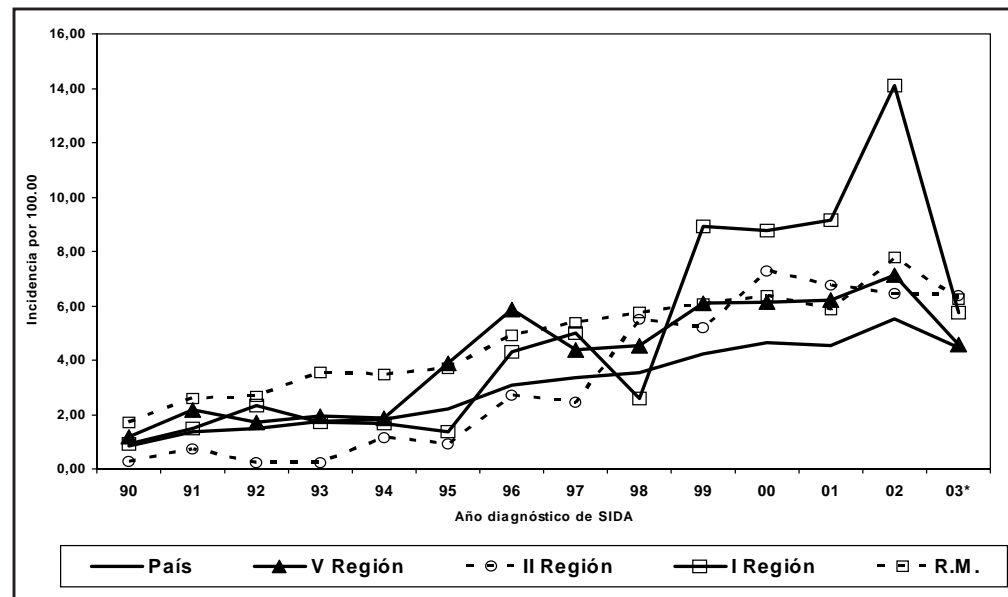

Información al 31 de diciembre 2003. Proyecciones de población INE, Censo 1992.
Gráfico 5. Incidencia anual de infección por VIH en regiones seleccionadas. Chile, 1990-2003. Cifra preliminar debido a latencia en la notificación.
IV $^{\mathrm{a}}$ y VIII ${ }^{\mathrm{a}}$, cuyas cifras son similares a algunos Servicios de Salud de la Región Metropolitana.

La Tabla 5 muestra el número de casos de SIDA, vivos y fallecidos, con sus respectivas tasas/100.000 habitantes separados por sexo, como orientador de las necesidades asistenciales.

\section{Diferencia entre información nacional y local}

Debido a que la información sobre casos de SIDA e infección por VIH según Servicio de Salud de ocurrencia es un elemento para la proyección de las necesidades asistenciales, es necesario considerar que pueden existir diferencias en las cifras del nivel nacional con las de las personas bajo control en los niveles locales. Entre las razones para esta diferencia está el hecho que pueden corresponder a personas notificadas la primera vez por otro Servicio de Salud o en el sector privado, o personas que en algún momento fueron notificadas y hoy no se encuentran en control activo o a traslados entre Servicios de Salud, dada la larga evolución de los casos.

\section{Análisis de infección por VIH/SIDA según comuna de residencia}

También se incluyen los casos por comuna de residencia en ambos sexos para las 253 comunas del país que han reportado casos de infección por VIH y/o SIDA, de un total de 342, correspondiendo a $74 \%$ del total. Sin embargo, todas las regiones han informado casos a lo menos en alguna comuna. La clasificación de las comunas que han notificado casos de infección por VIH o SIDA en orden descendente se presenta en la Tabla 6. En primer lugar con la mayor tasa de incidencia de infección por VIH/SIDA se ubica la comuna de Santiago con 519,97 casos/100.000 habitantes, en segundo lugar la comuna de Providencia con 270,73 casos/100.000 habitantes y en tercer lugar se encuentra la comuna rural de Hualañe con 258,12 casos/100.000 habitantes, seguida de Cartagena con 226,78 casos/100.000 habitantes. Dentro de las diez primeras comunas clasificadas sólo una es rural, que corresponde a Hualañé, las 9 restantes son urbanas, ya que Cartagena sólo tiene $13 \%$ de ruralidad. De las 10 primeras comunas con mayores tasas de incidencia de infección por VIH/SIDA 7 corresponden a la Región Metropolitana, 2 a la $V^{\mathrm{a}}$ Región y una a la VII ${ }^{\mathrm{a}}$ Región.

\section{Distribución por sexo en casos de SIDA}

En el análisis de los casos de SIDA acumulados desde el inicio de la epidemia, la mayor proporción está centrada en los hombres, que constituyen el $88,7 \%$ de los casos de SIDA, $11,3 \%$ son mujeres (Gráfico 6). Existe un crecimiento relativo mayor de casos de SIDA en mujeres con relación a los hombres durante los últimos años, incluyendo todos los mecanismos de transmisión. El promedio de incremento anual de la incidencia en SIDA para el período 19982003 es $4,7 \%$ en las mujeres versus $3,0 \%$ en los hombres (Tabla 7).

Al analizar las notificaciones de infección asintomática para igual período por sexo, el incremento promedio en mujeres es de $7,3 \%$ versus $6,8 \%$ observado en hombres (Tabla 8 ). Una razón para explicar esta diferencia, podría ser la búsqueda activa en mujeres, como es el caso de 
las mujeres embarazadas y control de salud sexual o un aumento real de la incidencia de infección por VIH.

\section{Distribución por edad al diagnóstico de SIDA}

El principal grupo de edad afectado tiene entre 20 y 49 años y concentra el $84,4 \%$ de los casos. Los jóvenes y niños bajo 20 años de edad representan el 3,3\% y los adultos sobre 50 el $12,3 \%$. Al comparar entre sexos en orden decreciente por grupo de edad es igual pero con leves diferencias en las cifras porcentuales. Es así, que al estimar el porcentaje por sexo, encontramos que en hombres bajo 20 años de edad corresponde a $2,7 \%, 20-49$ años $85,2 \%$ y sobre 50 años $12,1 \%$. En mujeres, bajo 20 años de edad alcanzan a $8,3 \%$, 20-49 años $78,0 \%$ y sobre 50 años $13,7 \%$ (Gráfico 7).

\section{Categorías de exposición declaradas en casos de SIDA (Gráfico 8)}

Se analiza lo declarado por las personas, excluyendo a quienes no declaran categoría de exposición, situación en que se encuentra $7,2 \%$ del total de los casos notificados. Ante la declaración de más de una categoría, se aplica una jerarquización de acuerdo a la eficiencia de la vía en la

Tabla 4. Casos y tasas acumuladas de infección por VIH y SIDA, por Servicio de Salud de ocurrencia y sexo. Chile, $1984-2003 *$

\begin{tabular}{|c|c|c|c|c|c|c|c|c|}
\hline \multirow[t]{2}{*}{ Servicio de Salud } & \multicolumn{2}{|c|}{$\begin{array}{c}\text { Hombres } \\
\text { con VIH }\end{array}$} & \multicolumn{2}{|c|}{$\begin{array}{l}\text { Hombres } \\
\text { con SIDA }\end{array}$} & \multicolumn{2}{|c|}{$\begin{array}{c}\text { Mujeres } \\
\text { conVIH }\end{array}$} & \multicolumn{2}{|c|}{$\begin{array}{r}\text { Mujeres } \\
\text { con SIDA }\end{array}$} \\
\hline & Casos & Tasa & Casos & Tasa & Casos & Tasa & Casos & Tasa \\
\hline Arica & 131 & 141,99 & 95 & 102,97 & 36 & 40,06 & 10 & 11,13 \\
\hline Iquique & 92 & 103,31 & 86 & 96,57 & 12 & 14,17 & 12 & 14,17 \\
\hline Antofagasta & 170 & 78,56 & 146 & 67,47 & 51 & 24,26 & 19 & 9,04 \\
\hline Atacama & 29 & 23,27 & 19 & 15,25 & 13 & 11,03 & 7 & 5,94 \\
\hline Coquimbo & 156 & 59,90 & 110 & 42,24 & 37 & 14,07 & 17 & 6,46 \\
\hline Valparaíso/San Antonio & 483 & 230,31 & 406 & 193,59 & 117 & 53,74 & 48 & 22,05 \\
\hline Viña del Mar/Quillota & 180 & 46,00 & 230 & 58,77 & 62 & 14,87 & 48 & 11,51 \\
\hline Aconcagua & 45 & 44,42 & 71 & 70,09 & 21 & 20,76 & 11 & 10,87 \\
\hline M. Norte & 567 & 190,25 & 591 & 198,30 & 92 & 2,59 & 49 & 1,38 \\
\hline M. Occidente & 248 & 48,54 & 400 & 78,29 & 67 & 12,86 & 68 & 13,05 \\
\hline M. Central & 948 & 279,66 & 862 & 254,29 & 136 & 37,36 & 66 & 18,13 \\
\hline M. Oriente & 642 & 135,39 & 681 & 143,61 & 99 & 17,45 & 74 & 13,04 \\
\hline M. Sur & 559 & 110,10 & 650 & 128,03 & 119 & 21,75 & 79 & 14,44 \\
\hline M. Sur Oriente & 401 & 73,39 & 309 & 56,55 & 119 & 20,94 & 42 & 7,39 \\
\hline O’Higgins & 96 & 26,14 & 68 & 18,52 & 26 & 7,35 & 7 & 1,98 \\
\hline Maule & 122 & 28,11 & 127 & 29,27 & 44 & 10,38 & 37 & 8,73 \\
\hline Nuble & 43 & 19,90 & 64 & 29,62 & 7 & 3,25 & 6 & 2,78 \\
\hline Concepción/Arauco & 101 & 30,12 & 155 & 46,23 & 27 & 7,88 & 26 & 7,59 \\
\hline Talcahuano & 53 & 30,65 & 49 & 28,34 & 10 & 5,61 & 8 & 4,49 \\
\hline Bío-Bío & 23 & 13,55 & 31 & 18,26 & 6 & 3,63 & 6 & 3,63 \\
\hline Araucanía (Norte y Sur) & 78 & 19,20 & 90 & 22,16 & 32 & 7,91 & 20 & 4,95 \\
\hline Valdivia & 21 & 12,21 & 48 & 27,92 & 9 & 5,36 & 9 & 5,36 \\
\hline Osorno & 60 & 56,13 & 28 & 26,19 & 12 & 11,23 & 5 & 4,68 \\
\hline Llanchipal & 56 & 25,64 & 36 & 16,48 & 15 & 7,02 & 5 & 2,34 \\
\hline Aysén & 9 & 20,04 & 10 & 22,26 & 6 & 14,92 & 1 & 2,49 \\
\hline Magallanes & 20 & 25,43 & 16 & 20,34 & 6 & 8,56 & 2 & 2,85 \\
\hline Total & 5333 & 77,68 & 5378 & 78,34 & 1181 & 16,83 & 682 & 9,72 \\
\hline
\end{tabular}

Información al 31 de diciembre 2003.

Tasas/100.000 habitantes. Proyecciones de población INE, Censo 1992.

* Corresponde a Servicio de Salud de ocurrencia. 
transmisión, por ejemplo, si se asocia exposición por compartir jeringas durante la drogadicción inyectable y exposición sexual, se considera categoría de exposición sanguínea por prácticas asociadas al uso de drogas inyectables.

- Sexual: A lo largo del tiempo ha sido la principal categoría de exposición, con tendencia siempre a crecer, alcanzando al 2003 a $94,1 \%$ del total de casos. A diciembre 2003 el análisis de tendencia en el tiempo muestra que el mayor número de casos siguió concentrándose en la exposición homo/bisexual masculina. Se observa un crecimiento de la transmisión heterosexual tanto en mujeres como en hombres; la transmisión hombre-mujer sería más eficiente que la transmisión mujer-hombre, por lo tanto, el exceso de declaración de hombres heterosexuales respecto a mujeres heterosexuales es poco probable e indicaría una subnotificación de exposición homo-bisexual por parte de los hombres (Gráfico 9).

- Sanguínea: Alcanza a 4,3\% desde el inicio de la epidemia, esta vía de exposición tiende a disminuir, en el corte de diciembre de $2001 \mathrm{su}$ proporción fue de 4,6\%. El análisis de la transmisión sanguínea a través del tiempo muestra que la infección adquirida por prácticas asociadas al uso de drogas inyectables es hoy la fundamental dentro de esta vía de transmisión. La detección de anticuerpos anti-VIH se implementó en los bancos de sangre a partir del segundo semestre de 1987, frenando la exposición por transfusiones de sangre y otros productos hemoderivados ${ }^{3}$.

Tabla 5. Casos vivos/ fallecidos y tasas acumuladas de SIDA por Servicio de Salud de ocurrencia y sexo Chile, 1984 - 2003*

\begin{tabular}{|c|c|c|c|c|c|c|c|c|c|c|}
\hline S. Salud & Vivos & $\begin{array}{l}\text { Hombres } \\
\text { Fallecidos }\end{array}$ & S Tasa & Vivas & $\begin{array}{c}\text { Mujeres } \\
\text { Fallecidas }\end{array}$ & Tasa & Vivos & $\begin{array}{c}\text { Ambos } \\
\text { Fallecidos }\end{array}$ & Total & Tasa \\
\hline Arica & 46 & 49 & 102,97 & 7 & 3 & 11,13 & 53 & 52 & 105 & 57,65 \\
\hline Iquique & 32 & 54 & 96,57 & 5 & 7 & 14,17 & 37 & 61 & 98 & 56,41 \\
\hline Antofagasta & 54 & 92 & 67,47 & 5 & 14 & 9,04 & 59 & 106 & 165 & 38,67 \\
\hline Atacama & 4 & 15 & 15,25 & 2 & 5 & 5,94 & 6 & 20 & 26 & 10,72 \\
\hline Coquimbo & 38 & 72 & 42,24 & 6 & 11 & 6,46 & 44 & 83 & 127 & 24,26 \\
\hline Valparaíso/San Antonio & 99 & 307 & 193,59 & 14 & 34 & 22,05 & 113 & 341 & 454 & 106,21 \\
\hline Viña del Mar/Quillota & 62 & 168 & 58,77 & 14 & 34 & 11,51 & 76 & 202 & 278 & 34,39 \\
\hline Aconcagua & 27 & 44 & 70,09 & 3 & 8 & 10,87 & 30 & 52 & 82 & 40,50 \\
\hline M. Norte & 218 & 373 & 198,30 & 19 & 30 & 1,38 & 237 & 403 & 640 & 16,64 \\
\hline M. Occidente & 181 & 219 & 78,29 & 27 & 41 & 13,05 & 208 & 260 & 468 & 45,35 \\
\hline M. Central & 345 & 517 & 254,29 & 29 & 37 & 18,13 & 374 & 554 & 928 & 132,00 \\
\hline M. Oriente & 290 & 391 & 143,61 & 29 & 45 & 13,04 & 319 & 436 & 755 & 72,49 \\
\hline M. Sur & 184 & 466 & 128,03 & 17 & 62 & 14,44 & 201 & 528 & 729 & 69,11 \\
\hline M. Sur Oriente & 104 & 205 & 56,55 & 15 & 27 & 7,39 & 119 & 232 & 351 & 31,49 \\
\hline O’Higgins & 31 & 37 & 18,52 & 3 & 4 & 1,98 & 34 & 41 & 75 & 10,40 \\
\hline Maule & 31 & 96 & 29,27 & 11 & 26 & 8,73 & 42 & 122 & 164 & 19,11 \\
\hline Ñuble & 20 & 44 & 29,62 & 2 & 4 & 2,78 & 22 & 48 & 70 & 16,22 \\
\hline Concepción/Arauco & 61 & 94 & 46,23 & 12 & 14 & 7,59 & 73 & 108 & 181 & 26,70 \\
\hline Talcahuano & 11 & 38 & 28,34 & 3 & 5 & 4,49 & 14 & 43 & 57 & 16,24 \\
\hline Bío-Bío & 19 & 12 & 18,26 & 2 & 4 & 3,63 & 21 & 16 & 37 & 11,05 \\
\hline Araucanía (Norte y Sur) & 39 & 51 & 22,16 & 10 & 10 & 4,95 & 49 & 61 & 110 & 13,57 \\
\hline Valdivia & 17 & 31 & 27,92 & 3 & 6 & 5,36 & 20 & 37 & 57 & 16,77 \\
\hline Osorno & 4 & 24 & 26,19 & 0 & 5 & 4,68 & 4 & 29 & 33 & 15,44 \\
\hline LLanchipal & 18 & 18 & 16,48 & 0 & 5 & 2,34 & 18 & 23 & 41 & 9,49 \\
\hline Aysén & 3 & 7 & 22,26 & 1 & 0 & 2,49 & 4 & 7 & 11 & 12,92 \\
\hline Magallanes & 10 & 6 & 20,34 & 0 & 2 & 2,85 & 10 & 8 & 18 & 12,10 \\
\hline Total & 1.948 & 3.430 & 78,34 & 239 & 443 & 9,72 & 2.187 & 3.873 & 6.060 & 43,65 \\
\hline
\end{tabular}

Información al 31 de diciembre 2003.

Tasas/100.000 habitantes. Proyecciones de población INE, Censo 1992.

*Corresponde a Servicio de Salud de ocurrencia. 
Tabla 6. Casos y tasas acumulas de infección por VIH/SIDA por comunas. Chile, 1984-2003*

\begin{tabular}{|c|c|c|c|c|}
\hline & & Total & Población* & Tasa/100.000 hbts. \\
\hline 1 & Santiago & 1.201 & 230.977 & 519,97 \\
\hline 2 & Providencia & 301 & 111.182 & 270,73 \\
\hline 3 & Hualañé & 24 & 9.298 & 258,12 \\
\hline 4 & Cartagena & 27 & 11.906 & 226,78 \\
\hline 5 & Valparaíso & 616 & 282.840 & 217,79 \\
\hline 6 & San Miguel & 178 & 82.869 & 214,80 \\
\hline 7 & Conchalí & 315 & 152.919 & 205,99 \\
\hline 8 & Independencia & 156 & 77.794 & 200,53 \\
\hline 9 & Ñuñoa & 318 & 172.575 & 184,27 \\
\hline 10 & Recoleta & 299 & 164.767 & 181,47 \\
\hline 11 & Quilicura & 68 & 41.121 & 165,37 \\
\hline 12 & Arica & 270 & 169.456 & 159,33 \\
\hline 13 & Estación Central & 223 & 140.896 & 158,27 \\
\hline 14 & Quinta Normal & 177 & 116.349 & 152,13 \\
\hline 15 & San Joaquín & 171 & 114.017 & 149,98 \\
\hline 16 & Puente Alto & 379 & 254.673 & 148,82 \\
\hline 17 & San Felipe & 76 & 54.591 & 139,22 \\
\hline 18 & Viña del Mar & 388 & 285.454 & 135,92 \\
\hline 19 & La Cisterna & 128 & 94.712 & 135,15 \\
\hline 20 & Quilpué & 140 & 104.203 & 134,35 \\
\hline 21 & Macul & 162 & 120.708 & 134,21 \\
\hline 22 & Maipú & 339 & 256.550 & 132,14 \\
\hline 23 & Iquique & 200 & 151.677 & 131,86 \\
\hline 24 & La Serena & 153 & 120.816 & 126,64 \\
\hline 25 & Huechuraba & 77 & 61.784 & 124,63 \\
\hline 26 & Lo Espejo & 148 & 120.075 & 123,26 \\
\hline 27 & Peñalolén & 212 & 179.781 & 117,92 \\
\hline 28 & San Antonio & 92 & 78.158 & 117,71 \\
\hline 29 & Lo Prado & 130 & 110.933 & 117,19 \\
\hline 30 & Pedro Aguirre Cerda & 151 & 130.441 & 115,76 \\
\hline 31 & Renca & 146 & 128.972 & 113,20 \\
\hline 32 & La Florida & 369 & 328.881 & 112,20 \\
\hline 33 & Mejillones & 7 & 6.315 & 110,85 \\
\hline 34 & Pudahuel & 152 & 137.940 & 110,19 \\
\hline 35 & San Bernardo & 209 & 190.857 & 109,51 \\
\hline 36 & Las Condes & 227 & 208.063 & 109,10 \\
\hline 37 & El Bosque & 187 & 172.854 & 108,18 \\
\hline 38 & Paihuano & 4 & 3.772 & 106,04 \\
\hline 39 & San Pedro de Atacama & 3 & 2.829 & 106,04 \\
\hline 40 & La Granja & 139 & 133.285 & 104,29 \\
\hline 41 & La Pintana & 175 & 169.640 & 103,16 \\
\hline 42 & Quillota & 69 & 67.007 & 102,97 \\
\hline 43 & Casablanca & 17 & 16.590 & 102,47 \\
\hline 44 & Villa Alemana & 73 & 71.672 & 101,85 \\
\hline 45 & Antofagasta & 238 & 247.000 & 96,36 \\
\hline 46 & Cerro Navia & 149 & 155.735 & 95,68 \\
\hline
\end{tabular}


Tabla 6. (Continuación)

\begin{tabular}{|c|c|c|c|c|}
\hline & & Total & Población* & Tasa/100.000 hbts. \\
\hline 47 & San Ramón & 96 & 100.817 & 95,22 \\
\hline 48 & Talca & 162 & 171.287 & 94,58 \\
\hline 49 & Coquimbo & 115 & 122.766 & 93,67 \\
\hline 50 & San Pedro & 6 & 6.746 & 88,94 \\
\hline 51 & Calama & 108 & 121.807 & 88,66 \\
\hline 52 & El Tabo & 4 & 4.513 & 88,63 \\
\hline 53 & Pirque & 10 & 11.368 & 87,97 \\
\hline 54 & Los Andes & 43 & 49.747 & 86,44 \\
\hline 55 & Quintero & 15 & 17.796 & 84,29 \\
\hline 56 & El Quisco & 5 & 6.097 & 82,01 \\
\hline 57 & Vichuquén & 4 & 4.931 & 81,12 \\
\hline 58 & Curanilahue & 27 & 33.631 & 80,28 \\
\hline 59 & Colina & 42 & 52.769 & 79,59 \\
\hline 60 & Talagante & 35 & 44.908 & 77,94 \\
\hline 61 & San José de Maipo & 9 & 11.646 & 77,28 \\
\hline 62 & La Reina & 71 & 92.410 & 76,83 \\
\hline 63 & Rancagua & 143 & 187.324 & 76,34 \\
\hline 64 & Tocopilla & 19 & 24.985 & 76,05 \\
\hline 65 & Osorno & 94 & 127.769 & 73,57 \\
\hline 66 & Isla de Pascua & 2 & 2.764 & 72,36 \\
\hline 67 & Camiña & 1 & 1.422 & 70,32 \\
\hline 68 & Cerrillos & 51 & 72.649 & 70,20 \\
\hline 69 & Sierra Gorda & 1 & 1.425 & 70,18 \\
\hline 70 & Concepción & 142 & 206.839 & 68,65 \\
\hline 71 & El Monte & 15 & 21.882 & 68,55 \\
\hline 72 & Algarrobo & 4 & 5.968 & 67,02 \\
\hline 73 & Castro & 20 & 29.931 & 66,82 \\
\hline 74 & Huayco & 5 & 7.516 & 66,52 \\
\hline 75 & Puchuncaví & 7 & 10.661 & 65,66 \\
\hline 76 & Vitacura & 52 & 79.375 & 65,51 \\
\hline 77 & Pozo Almonte & 4 & 6.322 & 63,27 \\
\hline 78 & Lo Barnechea & 31 & 50.062 & 61,92 \\
\hline 79 & La Calera & 28 & 45.776 & 61,17 \\
\hline 80 & San Gregorio & 1 & 1.643 & 60,86 \\
\hline 81 & Limache & 21 & 34.839 & 60,28 \\
\hline 82 & Aysén & 11 & 19.090 & 57,62 \\
\hline 83 & Freirina & 3 & 5.221 & 57,46 \\
\hline 84 & Temuco & 113 & 197.236 & 57,29 \\
\hline 85 & Ercilla & 5 & 8.842 & 56,55 \\
\hline 86 & Peñaflor & 28 & 50.148 & 55,83 \\
\hline 87 & Chillán & 83 & 149.510 & 55,51 \\
\hline 88 & Pumanque & 2 & 3.773 & 53,01 \\
\hline 89 & Concón & 10 & 18.872 & 52,99 \\
\hline 90 & Villarrica & 19 & 35.867 & 52,97 \\
\hline 91 & Corral & 3 & 5.765 & 52,04 \\
\hline 92 & Placilla & 4 & 7.799 & 51,29 \\
\hline 93 & Panquehue & 3 & 5.900 & 50,85 \\
\hline 94 & Calera de Tango & 6 & 11.843 & 50,66 \\
\hline
\end{tabular}


Tabla 6. (Continuación)

\begin{tabular}{|c|c|c|c|c|}
\hline & & Total & Población* & Tasa/100.000 hbts. \\
\hline 95 & Coronel & 42 & 83.426 & 50,34 \\
\hline 96 & Laja & 12 & 24.350 & 49,28 \\
\hline 97 & Antuco & 2 & 4.062 & 49,24 \\
\hline 98 & Graneros & 11 & 22.453 & 48,99 \\
\hline 99 & Llanquihue & 7 & 14.386 & 48,66 \\
\hline 100 & Valdivia & 57 & 122.168 & 46,66 \\
\hline 101 & Puerto Montt & 60 & 129.970 & 46,16 \\
\hline 102 & Los Vilos & 7 & 15.805 & 44,29 \\
\hline 103 & San Francisco de Mostazal & 8 & 18.138 & 44,11 \\
\hline 104 & Linares & 34 & 77.316 & 43,98 \\
\hline 105 & La Ligua & 12 & 27.322 & 43,92 \\
\hline 106 & Zapallar & 2 & 4.554 & 43,92 \\
\hline 107 & Maule & 6 & 13.769 & 43,58 \\
\hline 108 & Santa María & 5 & 11.575 & 43,20 \\
\hline 109 & Talcahuano & 107 & 248.543 & 43,05 \\
\hline 110 & Tierra Amarilla & 5 & 11.724 & 42,65 \\
\hline 111 & Buin & 22 & 52.792 & 41,67 \\
\hline 112 & Vicuña & 9 & 21.660 & 41,55 \\
\hline 113 & San Clemente & 15 & 36.414 & 41,19 \\
\hline 114 & Victoria & 13 & 32.979 & 39,42 \\
\hline 115 & San Javier & 14 & 35.587 & 39,34 \\
\hline 116 & Putaendo & 5 & 12.806 & 39,04 \\
\hline 117 & Til Til & 5 & 12.838 & 38,95 \\
\hline 118 & Punta Arenas & 43 & 113.666 & 37,83 \\
\hline 119 & Quinta de Tilcoco & 4 & 10.782 & 37,10 \\
\hline 120 & Arauco & 11 & 29.657 & 37,09 \\
\hline 121 & Taltal & 4 & 10.852 & 36,86 \\
\hline 122 & Curacaví & 7 & 19.053 & 36,74 \\
\hline 123 & Rengo & 16 & 43.617 & 36,68 \\
\hline 124 & María Elena & 5 & 13.660 & 36,60 \\
\hline 125 & Lebú & 9 & 24.748 & 36,37 \\
\hline 126 & Bulnes & 7 & 19.713 & 35,51 \\
\hline 127 & Coyhaique & 15 & 43.297 & 34,64 \\
\hline 128 & Paine & 13 & 37.529 & 34,64 \\
\hline 129 & Coínco & 2 & 5.823 & 34,35 \\
\hline 130 & Gorbea & 5 & 14.652 & 34,13 \\
\hline 131 & Loncoche & 8 & 23.643 & 33,84 \\
\hline 132 & Portezuelo & 2 & 5.970 & 33,50 \\
\hline 133 & Caldera & 4 & 12.061 & 33,16 \\
\hline 134 & Toltén & 4 & 12.061 & 33,16 \\
\hline 135 & Panguipulli & 10 & 30.162 & 33,15 \\
\hline 136 & Machalí & 8 & 24.152 & 33,12 \\
\hline 137 & Lota & 16 & 50.256 & 31,84 \\
\hline 138 & Olmué & 4 & 12.603 & 31,74 \\
\hline 139 & Río Negro & 5 & 16.026 & 31,20 \\
\hline 140 & Fresia & 4 & 13.013 & 30,74 \\
\hline 141 & Copiapó & 31 & 100.907 & 30,72 \\
\hline 142 & San Juan de la Costa & 3 & 9.778 & 30,68 \\
\hline
\end{tabular}


Tabla 6. (Continuación)

\begin{tabular}{|c|c|c|c|c|}
\hline & & Total & Población* & Tasa/100.000 hbts. \\
\hline 143 & San Ignacio & 5 & 16.499 & 30,30 \\
\hline 144 & Puerto Varas & 8 & 26.529 & 30,16 \\
\hline 145 & Llay-Llay & 6 & 20.276 & 29,59 \\
\hline 146 & Isla de Maipo & 6 & 20.344 & 29,49 \\
\hline 147 & Lago Ranco & 3 & 10.460 & 28,68 \\
\hline 148 & La Higuera & 1 & 3.498 & 28,59 \\
\hline 149 & Lampa & 7 & 25.033 & 27,96 \\
\hline 150 & Los Ángeles & 39 & 140.535 & 27,75 \\
\hline 151 & Carahue & 7 & 25.500 & 27,45 \\
\hline 152 & Nacimiento & 7 & 25.994 & 26,93 \\
\hline 153 & San Pablo & 3 & 11.178 & 26,84 \\
\hline 154 & Nogales & 5 & 18.669 & 26,78 \\
\hline 155 & Chile Chico & 1 & 3.757 & 26,62 \\
\hline 156 & Olivar & 3 & 11.332 & 26,47 \\
\hline 157 & Melipilla & 21 & 80.255 & 26,17 \\
\hline 158 & Yungay & 4 & 15.290 & 26,16 \\
\hline 159 & Pelarco & 2 & 7.648 & 26,15 \\
\hline 160 & Papudo & 1 & 3.896 & 25,67 \\
\hline 161 & Rauco & 2 & 7.822 & 25,57 \\
\hline 162 & Pencahue & 2 & 7.854 & 25,46 \\
\hline 163 & Molina & 9 & 35.674 & 25,23 \\
\hline 164 & Curicó & 26 & 104.113 & 24,97 \\
\hline 165 & Chiguayante & 14 & 56.371 & 24,84 \\
\hline 166 & Penco & 10 & 40.359 & 24,78 \\
\hline 167 & Curepto & 3 & 12.285 & 24,42 \\
\hline 168 & Coelemu & 4 & 16.630 & 24,05 \\
\hline 169 & Santa Cruz & 7 & 29.258 & 23,93 \\
\hline 170 & Río Claro & 3 & 12.591 & 23,83 \\
\hline 171 & Las Cabras & 4 & 17.738 & 22,55 \\
\hline 172 & Cauquenes & 9 & 40.279 & 22,34 \\
\hline 173 & Tomé & 11 & 49.284 & 22,32 \\
\hline 174 & Curacautín & 4 & 18.135 & 22,06 \\
\hline 175 & Diego de Almagro & 6 & 27.515 & 21,81 \\
\hline 176 & Purén & 3 & 13.917 & 21,56 \\
\hline 177 & Ovalle & 18 & 84.982 & 21,18 \\
\hline 178 & Vallenar & 10 & 47.248 & 21,16 \\
\hline 179 & San Carlos & 10 & 48.129 & 20,78 \\
\hline 180 & Requínoa & 4 & 19.432 & 20,58 \\
\hline 181 & Coltauco & 3 & 15.205 & 19,73 \\
\hline 182 & Porvenir & 1 & 5.104 & 19,59 \\
\hline 183 & Yumbel & 4 & 20.460 & 19,55 \\
\hline 184 & Traiguén & 4 & 20.622 & 19,40 \\
\hline 185 & Florida & 2 & 10.437 & 19,16 \\
\hline 186 & Quilleco & 2 & 10.492 & 19,06 \\
\hline 187 & Nueva Imperial & 7 & 36.878 & 18,98 \\
\hline 188 & La Cruz & 2 & 10.771 & 18,57 \\
\hline 189 & Cabrero & 4 & 21.705 & 18,43 \\
\hline 190 & Quirihue & 2 & 10.971 & 18,23 \\
\hline
\end{tabular}


Tabla 6. (Continuación)

\begin{tabular}{|c|c|c|c|c|}
\hline & & Total & Población* & Tasa/100.000 hbts. \\
\hline 191 & Río Bueno & 6 & 32.981 & 18,19 \\
\hline 192 & Colbún & 3 & 16.950 & 17,70 \\
\hline 193 & Collipulli & 4 & 22.767 & 17,57 \\
\hline 194 & Curarrehue & 1 & 5.978 & 16,73 \\
\hline 195 & Santa Juana & 2 & 11.957 & 16,73 \\
\hline 196 & Malloa & 2 & 12.252 & 16,32 \\
\hline 197 & San Pedro de la Paz & 11 & 67.817 & 16,22 \\
\hline 198 & Marchihue & 1 & 6.209 & 16,11 \\
\hline 199 & Santo Domingo & 1 & 6.218 & 16,08 \\
\hline 200 & Pitrufquén & 3 & 20.026 & 14,98 \\
\hline 201 & Hijuelas & 2 & 13.938 & 14,35 \\
\hline 202 & Longaví & 4 & 28.018 & 14,28 \\
\hline 203 & Pucón & 2 & 14.356 & 13,93 \\
\hline 204 & Combarbalá & 2 & 14.382 & 13,91 \\
\hline 205 & Illapel & 4 & 29.007 & 13,79 \\
\hline 206 & Cañete & 4 & 29.323 & 13,64 \\
\hline 207 & Coihueco & 3 & 22.585 & 13,28 \\
\hline 208 & Villa Alegre & 2 & 15.150 & 13,20 \\
\hline 209 & Freire & 3 & 22.997 & 13,05 \\
\hline 210 & Dalcahue & 1 & 7.763 & 12,88 \\
\hline 211 & San Fernando & 7 & 56.368 & 12,42 \\
\hline 212 & Pichidegua & 2 & 16.594 & 12,05 \\
\hline 213 & Negrete & 1 & 8.347 & 11,98 \\
\hline 214 & Sagrada Familia & 2 & 16.894 & 11,84 \\
\hline 215 & Maullín & 2 & 17.115 & 11,69 \\
\hline 216 & Punitaqui & 1 & 8.723 & 11,46 \\
\hline 217 & Cabildo & 2 & 17.520 & 11,42 \\
\hline 218 & Paillaco & 2 & 18.152 & 11,02 \\
\hline 219 & Lonquimay & 1 & 9.099 & 10,99 \\
\hline 220 & Cunco & 2 & 18.339 & 10,91 \\
\hline 221 & Renaico & 1 & 9.197 & 10,87 \\
\hline 222 & Chanco & 1 & 9.492 & 10,54 \\
\hline 223 & San Nicolás & 1 & 9.495 & 10,53 \\
\hline 224 & Parral & 4 & 38.067 & 10,51 \\
\hline 225 & Lautaro & 3 & 28.725 & 10,44 \\
\hline 226 & Calle Larga & 1 & 9.860 & 10,14 \\
\hline 227 & Constitución & 4 & 40.340 & 9,92 \\
\hline 228 & Purranque & 2 & 20.176 & 9,91 \\
\hline 229 & Pichilemu & 1 & 10.510 & 9,51 \\
\hline 230 & Catemu & 1 & 11.295 & 8,85 \\
\hline 231 & Romeral & 1 & 11.490 & 8,70 \\
\hline 232 & San Esteban & 1 & 12.153 & 8,23 \\
\hline 233 & Andacollo & 1 & 12.246 & 8,17 \\
\hline 234 & Peumo & 1 & 12.843 & 7,79 \\
\hline 235 & Ñiquén & 1 & 13.156 & 7,60 \\
\hline 236 & Futrono & 1 & 14.048 & 7,12 \\
\hline 237 & Galvarino & 1 & 14.076 & 7,10 \\
\hline 238 & El Carmen & 1 & 14.161 & 7,06 \\
\hline
\end{tabular}


Tabla 6. (Continuación)

\begin{tabular}{llrcc}
\hline & & Total & Población* & Tasa/100.000 hbts. \\
\hline 239 & Monte Patria & 2 & 28.374 & 7,05 \\
240 & Puerto Saavedra & 1 & 14.432 & 6,93 \\
241 & Quillón & 1 & 14.562 & 6,87 \\
242 & Doñihue & 14.578 & 6,86 \\
243 & Mulchén & 29.934 & 6,68 \\
244 & Quellón & 2 & 15.055 & 6,64 \\
245 & Angol & 1 & 46.226 & 6,49 \\
246 & Hualqui & 16.156 & 6,19 \\
247 & Puerto Natales & 1 & 17.275 & 5,79 \\
248 & Entrelagos & 1 & 18.564 & 5,39 \\
249 & Ancud & 1 & 37.516 & 5,33 \\
250 & La Unión & 38.740 & 5,16 \\
251 & Vilcún & 2 & 20.887 & 4,79 \\
252 & Teno & 2 & 24.090 & 4,15 \\
253 & Chimbarongo & 1 & 30.665 & 3,26 \\
\hline
\end{tabular}

Información preliminar a diciembre 2003

*Chile: División Político-Administrativa y Censal 2001

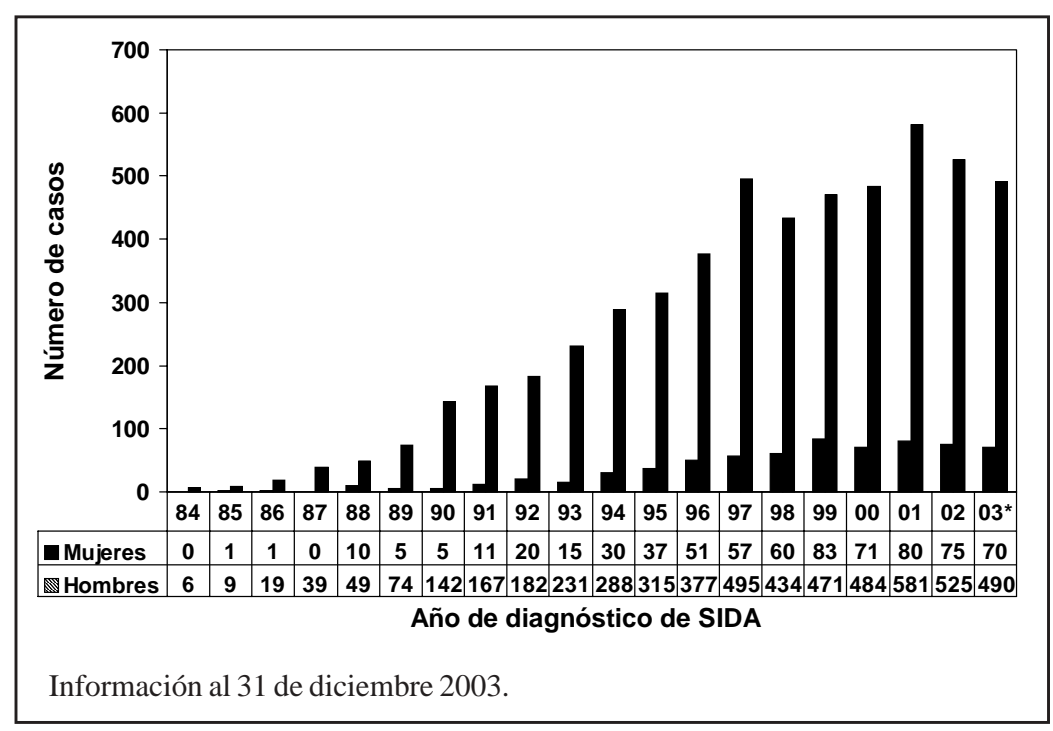

Gráfico 6. Casos de SIDA por año de diagnóstico y distribución según sexo. Chile, 1984-2003. Cifra preliminar debido a latencia en la notificación.
- Vertical: Corresponde al 1,6\% dentro del total de casos. El Comité Nacional de SIDA Pediátrico (SOCHIPE) registra a septiembre 2004 como expuestos a la transmisión vertical un total acumulado de 871 casos, de los cuales 213 adquirieron la infección por VIH (24,5\%), 588 no lo hicieron $(67,5 \%)$ y 70 están como indeterminados (8\%). En relación al año anterior el porcentaje de positivos disminuyó en 2,4\% (Gráfico 10).
El protocolo de prevención de la transmisión vertical de la infección por VIH ACTG 076, comenzó a usarse en Chile a partir de 1996. La transmisión vertical hasta 1994 fue de 35,4\%. En los inicios de aplicación del protocolo (19951997) en un total de 63 binomios madre/hijo se alcanzó una transmisión de 9,5\%. La evaluación en los años posteriores (1998-2003) reveló que de un total de 251 binomios, 2,4\% de los hijos resultaron infectados*.

\footnotetext{
* Comunicación personal obtenida del Comité de SIDA Pediátrico de la Sociedad Chilena de Pediatría. Santiago. Noviembre 2003.
} 
Tabla 7. Número de casos y tasa de SIDA por año de diagnóstico y sexo. Chile, 1984 - 2003*

\begin{tabular}{|c|c|c|c|c|c|c|}
\hline \multirow[t]{2}{*}{ Año } & \multicolumn{2}{|c|}{ Hombres } & \multicolumn{2}{|c|}{ Mujeres } & \multicolumn{2}{|c|}{ Total } \\
\hline & Casos & Tasa & Casos & Tasa & Casos & Tasa \\
\hline 1984 & 6 & 0,10 & 0 & - & 6 & 0,05 \\
\hline 85 & 9 & 0,15 & 1 & 0,02 & 10 & 0,08 \\
\hline 86 & 19 & 0,31 & 1 & 0,02 & 20 & 0,16 \\
\hline 87 & 39 & 0,63 & 0 & - & 39 & 0,31 \\
\hline 88 & 49 & 0,78 & 10 & 0,16 & 59 & 0,47 \\
\hline 89 & 74 & 1,16 & 5 & 0,08 & 79 & 0,61 \\
\hline 1990 & 142 & 2,19 & 5 & 0,08 & 147 & 1,12 \\
\hline 91 & 167 & 2,54 & 11 & 0,16 & 178 & 1,34 \\
\hline 92 & 182 & 2,72 & 20 & 0,29 & 202 & 1,49 \\
\hline 93 & 231 & 3,39 & 15 & 0,22 & 246 & 1,79 \\
\hline 94 & 288 & 4,16 & 30 & 0,42 & 318 & 2,27 \\
\hline 95 & 315 & 4,48 & 37 & 0,52 & 352 & 2,48 \\
\hline 96 & 377 & 5,28 & 51 & 0,70 & 428 & 2,97 \\
\hline 97 & 495 & 6,84 & 57 & 0,77 & 552 & 3,78 \\
\hline 98 & 434 & 5,92 & 60 & 0,80 & 494 & 3,33 \\
\hline 99 & 471 & 6,34 & 83 & 1,09 & 554 & 3,69 \\
\hline 2000 & 484 & 6,43 & 71 & 0,92 & 555 & 3,65 \\
\hline 01 & 581 & 7,62 & 80 & 1,03 & 661 & 4,29 \\
\hline 02 & 525 & 7,05 & 75 & 0,95 & 600 & 3,92 \\
\hline $03^{*}$ & 490 & 6,27 & 70 & 0,88 & 560 & 3,55 \\
\hline Total & 5.378 & 78,34 & 682 & 9,72 & 6.060 & 43,65 \\
\hline
\end{tabular}

* Cifra preliminar debido a latencia de la notificación.

Información al 31 de diciembre de 2003.

Tasas/100.000 habitantes. Proyecciones de población INE, Censo 1992.

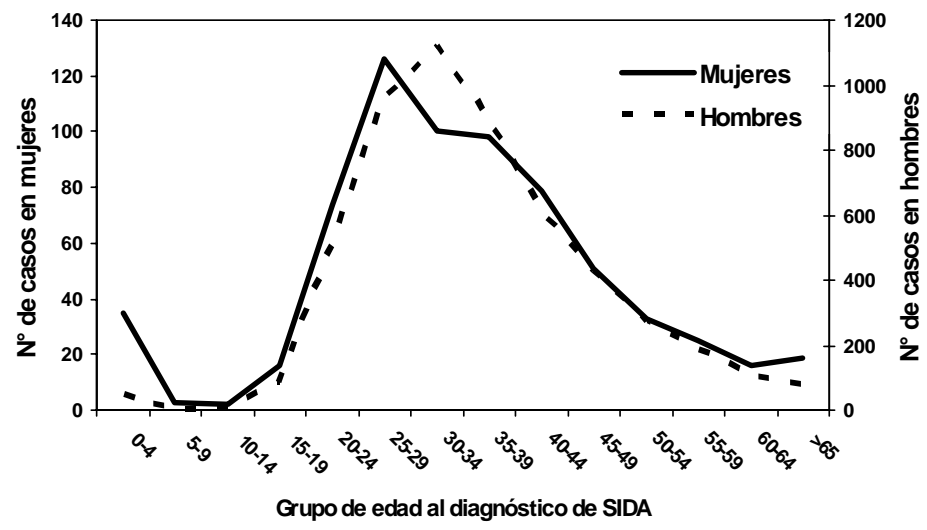

Información al 31 de diciembre 2003.
Gráfico 7. Casos acumulados de SIDA por grupo de edad y sexo. Chile, 1984-2003. Cifra preliminar debido a latencia en la notificación. 
Tabla 8. Número de casos y tasa de infección asintomática por año de diagnóstico y sexo Chile, 1984 - 2003*

\begin{tabular}{|c|c|c|c|c|c|c|}
\hline \multirow[t]{2}{*}{ Año } & \multicolumn{2}{|c|}{ Hombres } & \multicolumn{2}{|c|}{ Mujeres } & \multicolumn{2}{|c|}{ Total } \\
\hline & Casos & Tasa & Casos & Tasa & Casos & Tasa \\
\hline 1984 & 0 & - & 0 & - & 0 & - \\
\hline 85 & 1 & 0,02 & 0 & - & 1 & 0,01 \\
\hline 86 & 6 & 0,10 & 0 & - & 6 & 0,05 \\
\hline 87 & 22 & 0,36 & 3 & 0,05 & 25 & 0,20 \\
\hline 88 & 34 & 0,54 & 9 & 0,14 & 43 & 0,34 \\
\hline 89 & 66 & 1,04 & 7 & 0,11 & 73 & 0,57 \\
\hline 1990 & 95 & 1,47 & 15 & 0,23 & 110 & 0,84 \\
\hline 91 & 159 & 2,42 & 24 & 0,36 & 183 & 1,37 \\
\hline 92 & 177 & 2,64 & 26 & 0,38 & 203 & $1, .50$ \\
\hline 93 & 210 & 3,08 & 31 & 0,45 & 241 & 1,75 \\
\hline 94 & 212 & 3,06 & 42 & 0,59 & 254 & 1,82 \\
\hline 95 & 268 & 3,81 & 45 & 0,63 & 313 & 2,20 \\
\hline 96 & 356 & 4,99 & 88 & 1,21 & 444 & 3,08 \\
\hline 97 & 401 & 5,54 & 91 & 1,23 & 492 & 3,36 \\
\hline 98 & 427 & 5,82 & 101 & 1,35 & 528 & 3,56 \\
\hline 99 & 519 & 6,98 & 116 & 1,53 & 635 & 4,23 \\
\hline 2000 & 571 & 7,58 & 138 & 1,80 & 709 & 4,66 \\
\hline 01 & 558 & 7,32 & 140 & 1,80 & 698 & 4,53 \\
\hline 02 & 692 & 9,29 & 169 & 2,15 & 861 & 5,62 \\
\hline $03 *$ & 559 & 7,16 & 136 & 1,71 & 695 & 4,41 \\
\hline Total & 5.333 & 77,68 & 1.181 & 16,83 & 6.514 & 46,92 \\
\hline
\end{tabular}

* Cifra preliminar debido a latencia de la notificación.

Información al 31 de diciembre de 2003.

Tasas/100.000 habitantes. Proyecciones de población INE, Censo1992.

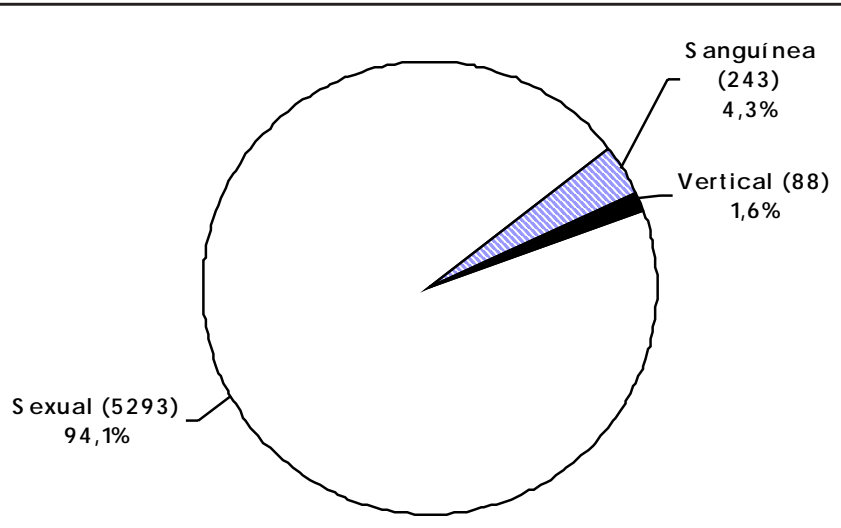

Información al 31 de diciembre 2003.

Excluye 435 casos que no declaran categoría de exposición,que corresponden a $7,2 \%$ del total de casos notificados.

Gráfico 8. Casos acumulados de SIDA por categoría de exposición declarada. Chile, 1984 - 2003. Cifra preliminar por latencia en la notificación. 


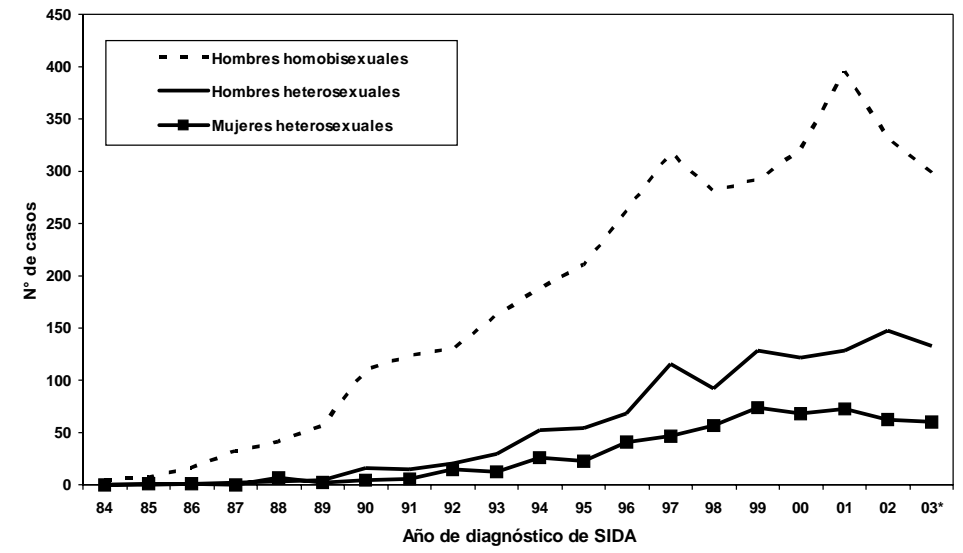

Información al 31 de diciembre 2003.
Gráfico 9. Casos de SIDA por transmision sexual y año de diagnóstico. Chile, 1984-2003. Cifra preliminar debido a latencia de la notificación.

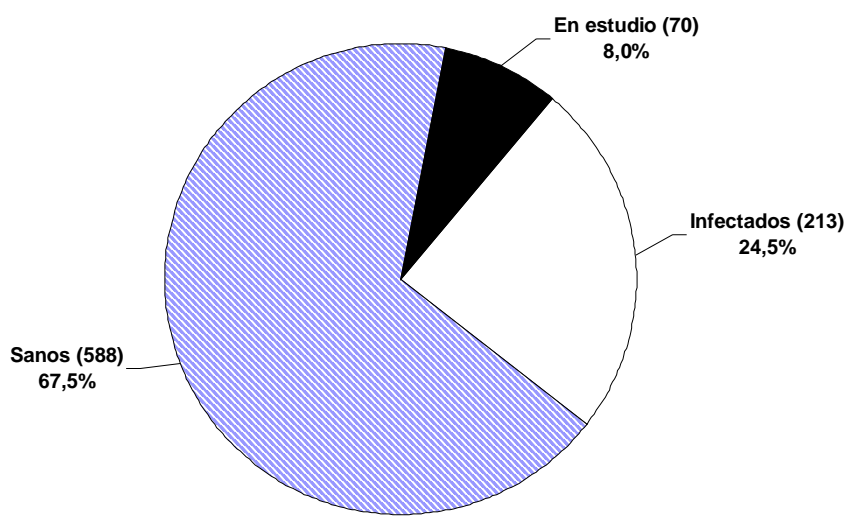

Información al 31 de septiembre 2004.

Cifras no consideran aplicación del Protocolo ACTG 076

Comité de SIDA pediátrico. Sociedad Chilena de Pediatría. 2003.
Gráfico 10. Transmisión vertical del VIH Chile. 1984 - 2004.
$\mathrm{Al}$ analizar la mortalidad por SIDA para ambos sexos en Chile, se observa una disminución en las tasas a partir de 1997 -producto del efecto parcial de las biterapias- hasta el 2001 cuando se produjo un aumento en la tasa que puede atribuirse a la falta de impacto de tratamiento generado por la incipiente cobertura con triterapia. La cobertura universal sólo podrá asegurarse (incluyendo el sector privado) a partir de la aprobación de la ley AUGE de la Reforma del Sector. Sin embargo, al comparar la mortalidad observada del período 1993-1997 y 1998-2003, se observa que para el primer segmento el incremento en la tasa de mortalidad promedio anual fue de 15,5\% y para el segundo período fue de $0,2 \%$. Es decir, existe un efecto de las terapias en la tendencia de la mortalidad, la cual al alcanzar el 2003 cobertura de $100 \%$ para los beneficiarios del Sistema Público, se espera que genere un impacto sostenido en el tiempo en la tasa de defunción por SIDA que se observaría transcurrido un período desconocido hasta ahora. A lo anterior se agrega la detección o diagnóstico tardío, que hace que el acceso a terapia a veces sea en etapas avanzadas de la enfermedad, impidiendo el impacto deseado. A la vez se informa por parte de los médicos tratantes* que en la actualidad los certificados de defunción son completados con las verdaderas

* Comunicación personal obtenida del Comité Científico Asesor. Santiago. Octubre 2003. 
causas de muerte a diferencia de años anteriores cuando se ocultaba en mayor proporción las causas reales de fallecimiento, lo que pretendía "proteger" a la familia o al paciente de discriminación. Superado esto, el sistema capta más defunciones reales por SIDA. Sumado a lo anterior están los cambios en el Departamento de Estadísticas del MINSAL, que mejoran los registros de defunción (Gráficos 11 y 12).

A la vez se observa una disminución en la letalidad por SIDA (fallecidos por SIDA entre aquellos que están enfermos) la cual fue sostenida hasta el 2000, el 2001 se produjo un aumento para luego nuevamente continuar el descenso. Por lo tanto, la tendencia de la curva de letalidad es claramente al descenso y explicada por los efectos de la TAR. Al igual que en la mortalidad, la letalidad está siendo afectada por el diagnóstico tardío, que implica que algunas personas infectadas por el VIH ingresan a tratamiento en etapas muy avanzadas de la enfermedad, aminorando el impacto de la terapia. A pesar de ello, se observa tendencia a disminución de la letalidad, explicado por el avance en cobertura y efectividad en la terapias (Gráficos 13 y 14).

También se incluye un análisis de los Años de Vida Potenciales Perdidos por SIDA (AVPP) para hombres de 20 a 49 años (Tabla 9). Este indicador se refiere a los años que la persona perdió de vivir debido a muerte prematura por SIDA considerando como límite máximo la Edad de Esperanza de Vida al Nacer, la cual ha ido aumentando fuertemente y en la actualidad, según estadísticas del INE para el período 20012002 se sitúa en 77,36 años para ambos sexos. Este segmento de la población es elegido para
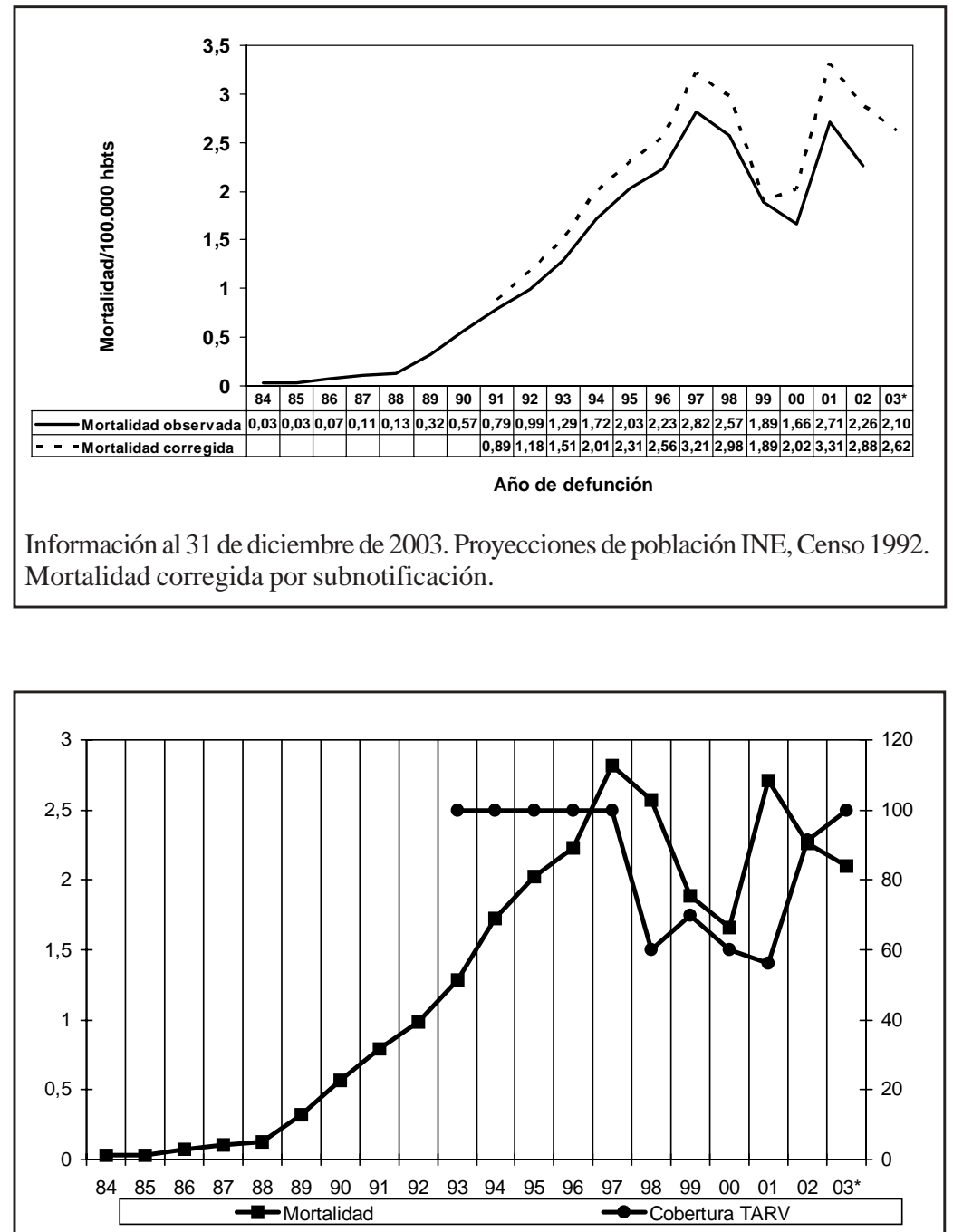

Información al 31 de diciembre 2003. Proyecciones de población INE, Censo 1992.
Gráfico 11. Mortalidad por SIDA. Chile, 1984-2003. Cifra preliminar debido a latencia en la notificación.
Gráfico 12. Cobertura de TARV y mortalidad por SIDA. Chile, 19842003. Cifra preliminar, debido a latencia en la notificación. 
hacer este indicador dado que es el más afectado por la epidemia, lo cual influye fuertemente no sólo en la economía por ser una edad de mucha productividad, sino también en los indicadores de salud como el cual se esta calculando, y en los indicadores socio-económicos como el ingreso familiar. Al observar la curva de los AVPP notamos que estos aumentaron significativamente desde el inicio de la epidemia en 1984 hasta 1997, año en que se registró una disminución que fue interrumpida en el 2001 donde se produjo un aumento con respecto al año anterior de 74,3\%; sin embargo, entre el 2001 y 2002 se registró un descenso de 16,2\%. Es esperable dado el aumento de cobertura de TARV y con esto una mejoría en la calidad de vida de las personas infectadas por VIH, lograr una tendencia a la disminución en los AVPP (Gráficos 15 y 16).

\section{Caracterización de la epidemia}

\section{Alcances metodológicos}

Se analizan la infección por VIH y SIDA conjuntamente para aumentar el tamaño del universo considerando que las diferencias en los parámetros estudiados entre VIH y SIDA son menores, es decir, no representan poblaciones distintas.

Para ver las tendencias de las distintas variables se muestran los casos de infección por VIH/ SIDA en todos los años a partir de 1984 cuando se registró el primer caso de SIDA, hasta el 2003, año con información preliminar por latencia de la información. Además se agrega un análisis para los casos de infección por VIH/SIDA acumulados desde 1984 al 2003 según las diferentes variables y por sexo.
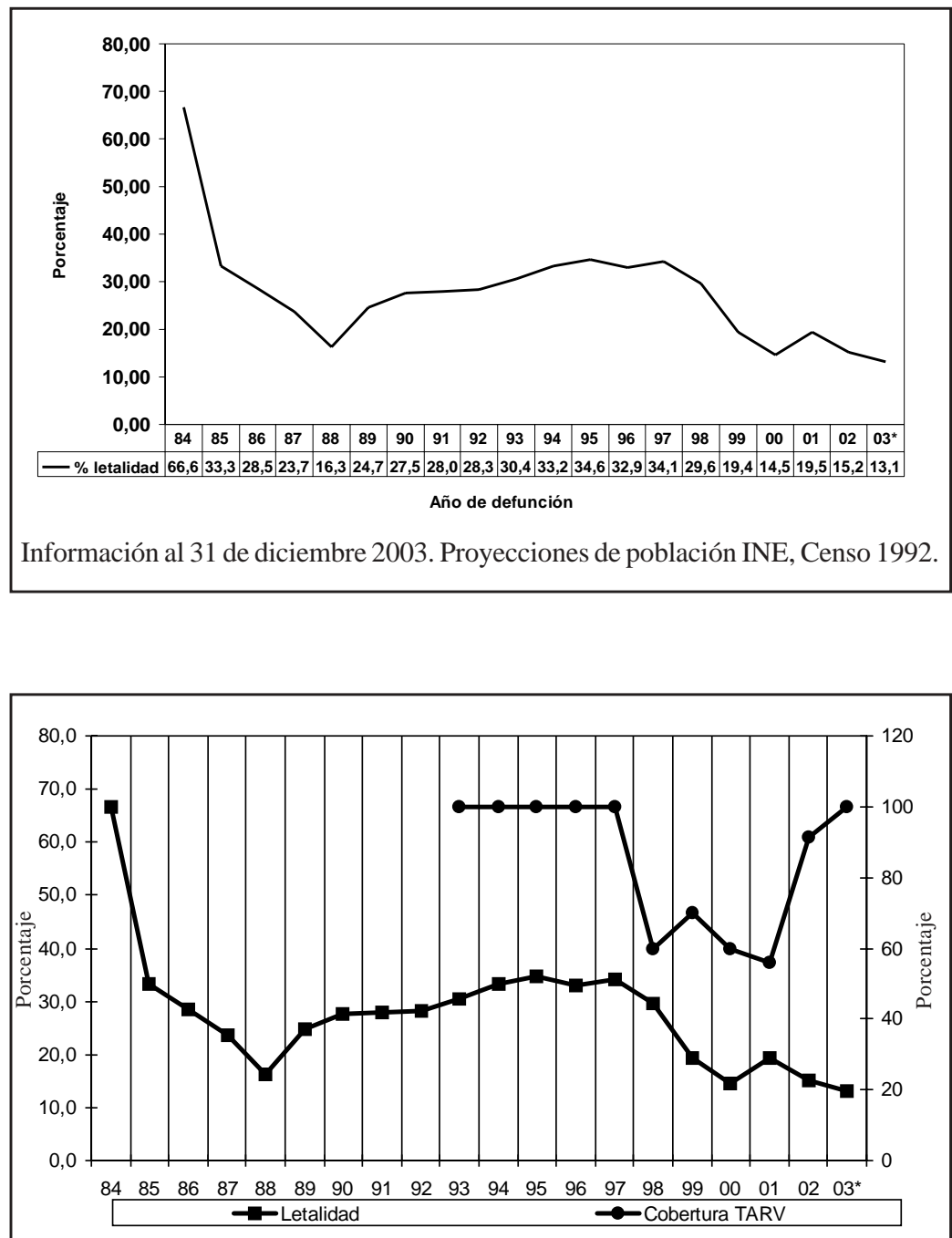

Información al 31 de diciembre 2003.
Gráfico 13. Letalidad por SIDA. Chile, 1984-2003. Cifra preliminar debido a latencia en la notificación.
Gráfico 14. Cobertura de TARV y letalidad causada por VIH/SIDA. Chile, 1984-2003. Cifra preliminar, debido a latencia en la notificación. 
Tabla 9. Años de vida potencialmente perdidos (AVPP). Hombres 20-49 años. Chile, 1984-2003*

\begin{tabular}{rr}
\hline Años & AVPP \\
\hline 1984 & 110 \\
85 & 108 \\
86 & 264 \\
87 & 211 \\
88 & 374 \\
89 & 1.177 \\
1990 & 1.996 \\
91 & 3.436 \\
92 & 4.035 \\
93 & 5.615 \\
94 & 7.559 \\
95 & 8.981 \\
96 & 9.383 \\
97 & 12.012 \\
98 & 11.465 \\
99 & 7.819 \\
2000 & 7.244 \\
01 & 12.626 \\
02 & 10.585 \\
$03 *$ & 9.129 \\
\hline
\end{tabular}

*Datos preliminares por latencia de la información. Información al 31 de diciembre 2003.

En la variable de tipo socio-económica -escolaridad-, se muestran todos los casos de infección por VIH/SIDA registrados separados para hombres y mujeres entre 15 y 49 años de edad, según las categorías Ninguna, Básica, Media, Superior y Desconocida.

En la otra variable socio-económica -ocupación-, también se registran todos los casos de infección por VIH/SIDA separados para hombres y mujeres entre 15 y 49 años de edad según las categorías Ejecutiva, Profesional, Oficinista, Operarios, Otras y desconocidas. En la categoría Otras se incluyen los estudiantes y dueñas de casa.

Para conocer la tendencia del Factor Principal de Exposición se grafican todas las vías de exposición separadas por sexo y para todos los años de la epidemia. Luego se adiciona la gráfica de análisis porcentual de las categorías acumuladas desde 1984 al 2002 y separadas por sexo.
El cálculo de edad se hace a la fecha de diagnóstico clínico de infección por VIH y/o SIDA. El análisis por grupo etario permite estimar la edad probable de infección; sin embargo, se debe considerar que el tiempo de evolución de la infección puede verse influenciado por la introducción de las terapias. Las categorías son: menores $(\leq 14$ años), jóvenes (15 a 24 años), adultos jóvenes (25 a 34 años), adultos (35 a 64 años) y adultos mayores (65 y más años de edad). Estos intervalos responden a la necesidad de vigilar la tendencia de la epidemia en los jóvenes de 15 a 24 años, indicador comprometido a seguir en el tiempo, en un acuerdo mundial, con ocasión de la Asamblea General Extraordinaria de Naciones Unidas sobre SIDA. También se agrega un análisis porcentual según categorías acumuladas para el período 1984-2003 según sexo.

Para determinar la ruralidad de las personas con infección por infección por VIH/SIDA se analizaron los casos notificados por año y comuna de residencia declarada. Se empleó el porcentaje de población rural de cada comuna como marcador de ruralidad* distribuyéndolas en quintiles. Luego se construyó el indicador porcentaje de comunas por cada quintil que ha notificado casos de infección por VIH/SIDA, según año de diagnóstico.

Se realizó a la vez, un ordenamiento de las comunas declaradas como residencia en las notificaciones según el Índice de Desarrollo Humano (IDH). Se entiende por desarrollo humano el proceso de ampliación de las capacidades de las personas. Las capacidades de las personas suelen ser múltiples y cambiar en el tiempo. Existen, sin embargo, algunas condiciones básicas y que son comunes a todas las sociedades y en todo tiempo como son tener una vida larga y sana, poseer los conocimientos necesarios para comprender y relacionarse con el entorno social y poseer los ingresos suficientes para acceder a un nivel de vida digna. La mirada del desarrollo humano intenta mostrar la acumulación de capacidades humanas incluyendo múltiples dimensiones que la diferencia de la pobreza, la cual hace hincapié en las carencias y limitado al aspecto económico.

Las variables incluidas en el IDH son salud (años de vida potencialmente perdidos), educación (alfabetismo, años de escolaridad promedio, matrícula combinada (cobertura escolar en cuatro niveles: preescolar, básica, media y superior)

\footnotetext{
* La definición de ruralidad corresponde a la utilizada por el INE y MIDEPLAN entendida como: Conjunto de viviendas concentradas o dispersas con 1.000 habitantes o menos o entre 1.001 y 2.000 habitantes con menos del $50 \%$ de su población económicamente activa, dedicada a actividades secundarias y/o terciarias.
} 


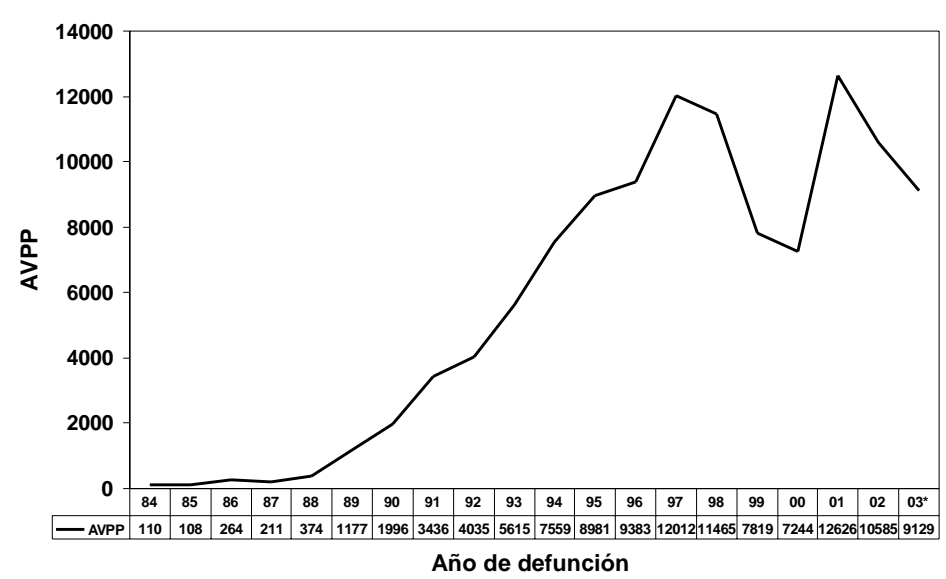

Información al 31 de diciembre 2003.
Gráfico 15. Años de vida potenciales perdidos (AVPP) por SIDA en hombres 20 a 49 años. Chile, 1984-2003. Cifra preliminar debido a latencia en la notificación.

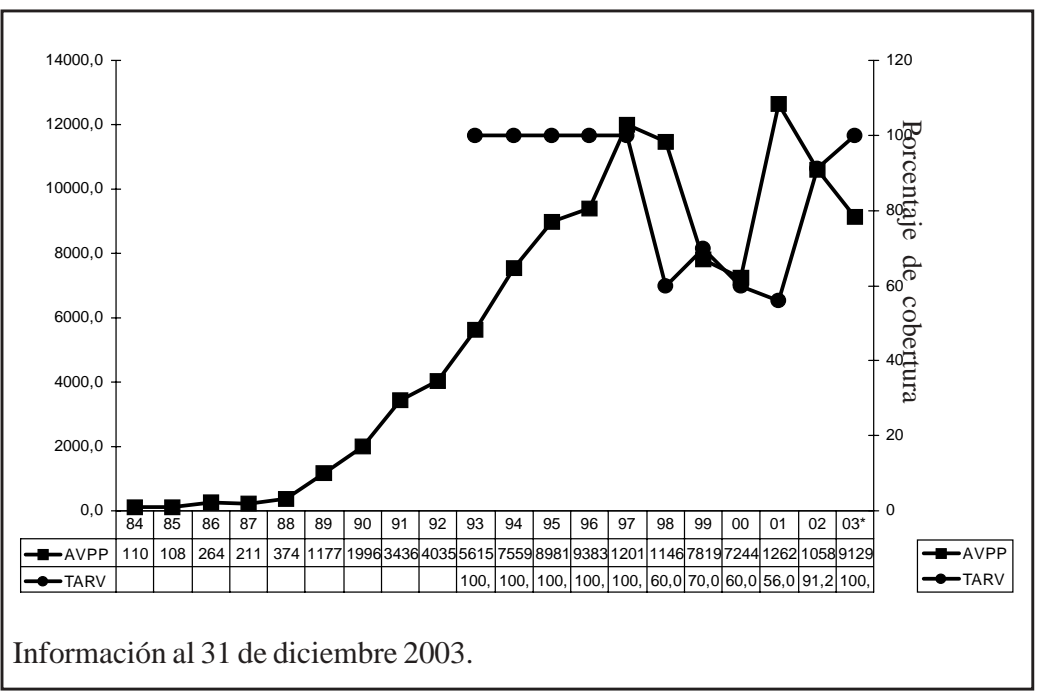

Gráfico 16. Años de vida potenciales perdidos por SIDA en hombres 20 a 49 años y porcentaje de coberturas de terapia anti-retroviral. Chile, 1984-2003. Cifra preliminar debido a latencia en la notificación. e ingresos (promedio per capita de los ingresos autónomos del hogar, desigualdad en la distribución del ingreso e incidencia de la pobreza de ingresos). Estas son las dimensiones que, en base a diferentes indicadores, se pretende recoger mediante el IDH.

En lo metodológico muestra cuán lejos o cerca se está de una meta ideal. En este estudio se incluyen 333 de las 341 comunas del país. Juan Fernández e Isla de Pascua han sido excluidas por su carácter insular. La comuna de San Rafael (VII ${ }^{\mathrm{a}}$ Región) se excluye por no estar representada estadísticamente en la Encuesta CASEN 1998, ser de creación posterior a 1992 y por no contar con información de defunciones que permita el cálculo de la variable AVPP. Las cinco comunas restantes, Con-Con, Chillán Viejo, San Pedro de la
Paz, Chiguayante y Padre Las Casas, fueron excluidas también, por ser de creación reciente y por lo tanto no contar con registros de defunciones.

El IDH tiene un rango entre 0,500 y 1,00 .

\section{Resultados de la caracterización}

La caracterización permite determinar cómo ha afectado y se ha diseminado el virus en distintas poblaciones entregando elementos básicos para la planificación y focalización de programas preventivos y de atención y para medir el impacto de las intervenciones. Los parámetros analizados indican la siguiente caracterización:

Feminización: Indica un crecimiento mayor a lo largo del tiempo de los casos de infección por $\mathrm{VIH}$ en mujeres en comparación a los hombres 
(incluyendo todas las categorías de exposición). Se observa el comportamiento del indicador razón hombre: mujer, el que muestra una tendencia a la disminución, es decir la brecha entre ambos sexos se acorta en el período 1990-2003 experimentando dentro de este período algunas fluctuaciones hasta aproximadamente el año 1996, a partir de la cual se mantiene estable en valores cercanos a 4 hombres por una mujer.

El análisis de igual indicador referido ahora a SIDA por año muestra una brecha mayor entre ambos sexos con una tendencia a la disminución y a la estabilización en valores cercanos a 7 hombres por una mujer (Gráfico 17).

Hetero-sexualización: La tendencia de la dis- tribución de casos a través del tiempo en mujeres que declararon exposición heterosexual, es a la mantención de ella como vía principal de notificación (Gráfico 18). A la vez se observa una tendencia al aumento de casos notificados por exposición heterosexual en hombres en quienes la vía homosexual es las más declarada (Gráfico 19).

Pauperización: Se refiere al desplazamiento de la epidemia hacia grupos poblacionales con menor nivel socioeconómico. Se evalúa a través del análisis de las variables escolaridad y ocupación contenidas en la notificación de casos.

Escolaridad: Al comparar la estructura del nivel de escolaridad en mujeres con infección por VIH/SIDA a través del tiempo, se observa un
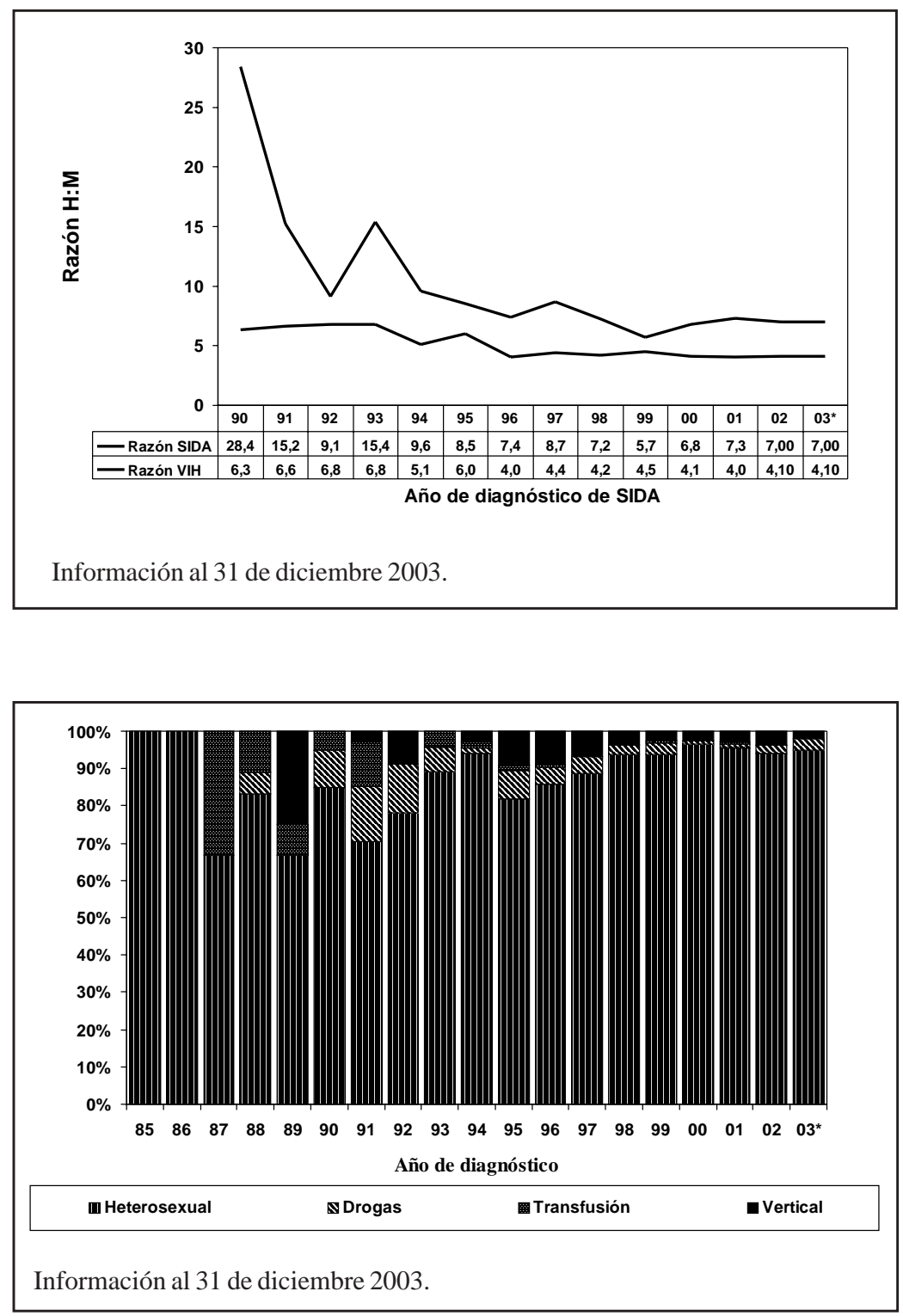

Gráfico 17. Proporción hombre: mujer en casos de SIDA e infección por VIH. Chile,1984-2003. Cifra preliminar debido a latencia de la notificación.
Gráfico 18. Casos de infección por VIH/SIDA y factor principal de exposición en mujeres. Chile, 19852003. Cifra preliminar debido a latencia de la notificación. 


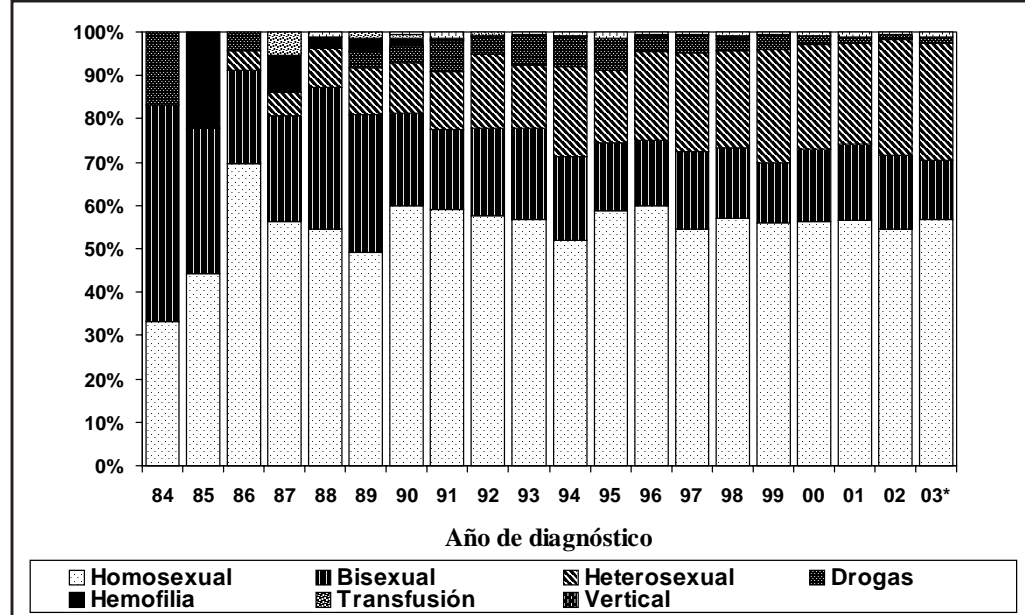

Información al 31 de diciembre 2003.
Gráfico 19. Casos de infección por VIH/SIDA y factor principal de exposición en hombres. Chile, 19842003. Cifra preliminar debido a latencia de la notificación.

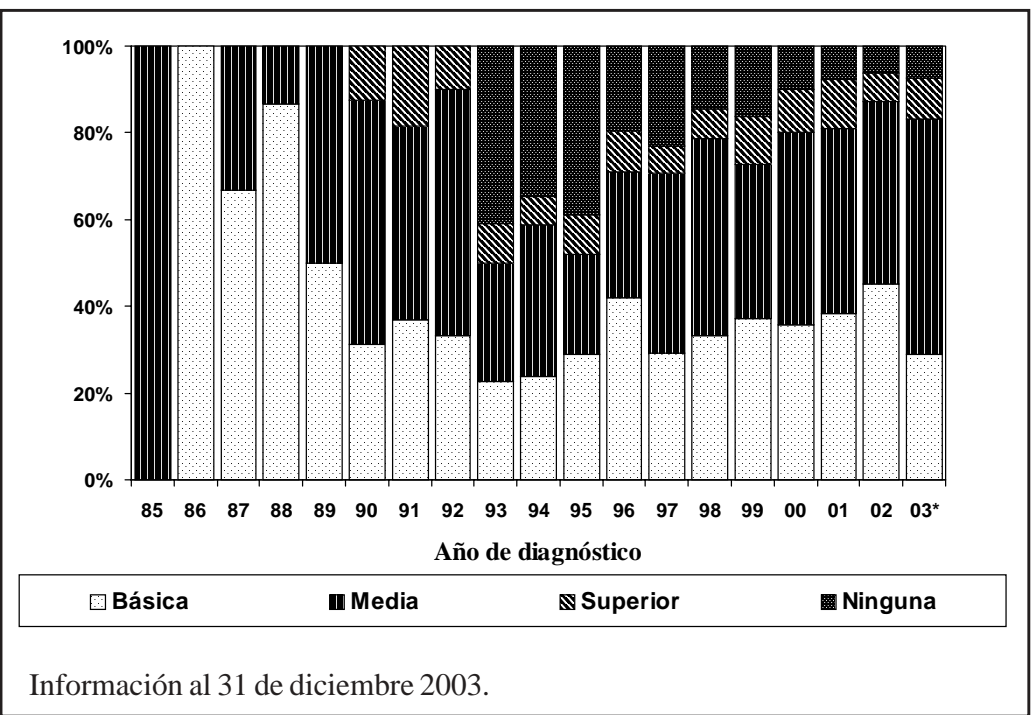

Gráfico 20. Casos de infección por VIH/SIDA y escolaridad en mujeres 15 a 49 años. Chile, 1985-2003. Cifra preliminar debido a latencia de la notificación. incremento porcentual en el número de casos de mujeres notificadas con educación básica, registrando una diferencia muy leve entre el nivel básico y medio, siendo mayor este último (Gráfico 20).

Igual análisis realizado para los hombres notificados muestra una mayor diferencia entre escolaridad básica y media, predominando este último. Al realizar un análisis porcentual de los casos de infección por VIH/SIDA acumulados durante el período 1984-2002 se ubica el mayor porcentaje en el nivel de escolaridad medio seguido por el nivel básico (Gráfico 21).

Ocupación: En las notificaciones de infección por VIH/SIDA acumuladas y por nivel de ocupación en mujeres de 15 a 49 años, durante la epidemia destaca el nivel de Operarias con un porcentaje para el período acumulado de $32,1 \%$ y Dueñas de casa $40,5 \%$, esta última representativa de la realidad nacional. En la categoría de Operarias desde el inicio de la epidemia se observa un aumento en las declaraciones de casos produciendo un aumento marcado de casos en 1995 y desde entonces a la fecha es la segunda categoría más declarada. La categoría Otro alcanza un 3,5\%. En el grupo de Oficinistas que presentan un $11,4 \%$ acumulado se produce un aumento de casos a partir de 1996 el cual disminuye a partir de 1999 (Gráfico 22).

En los hombres destaca el gran aumento en la categoría de Operarios el cual representa en forma acumulada un 55,9\% siendo esta categoría la 

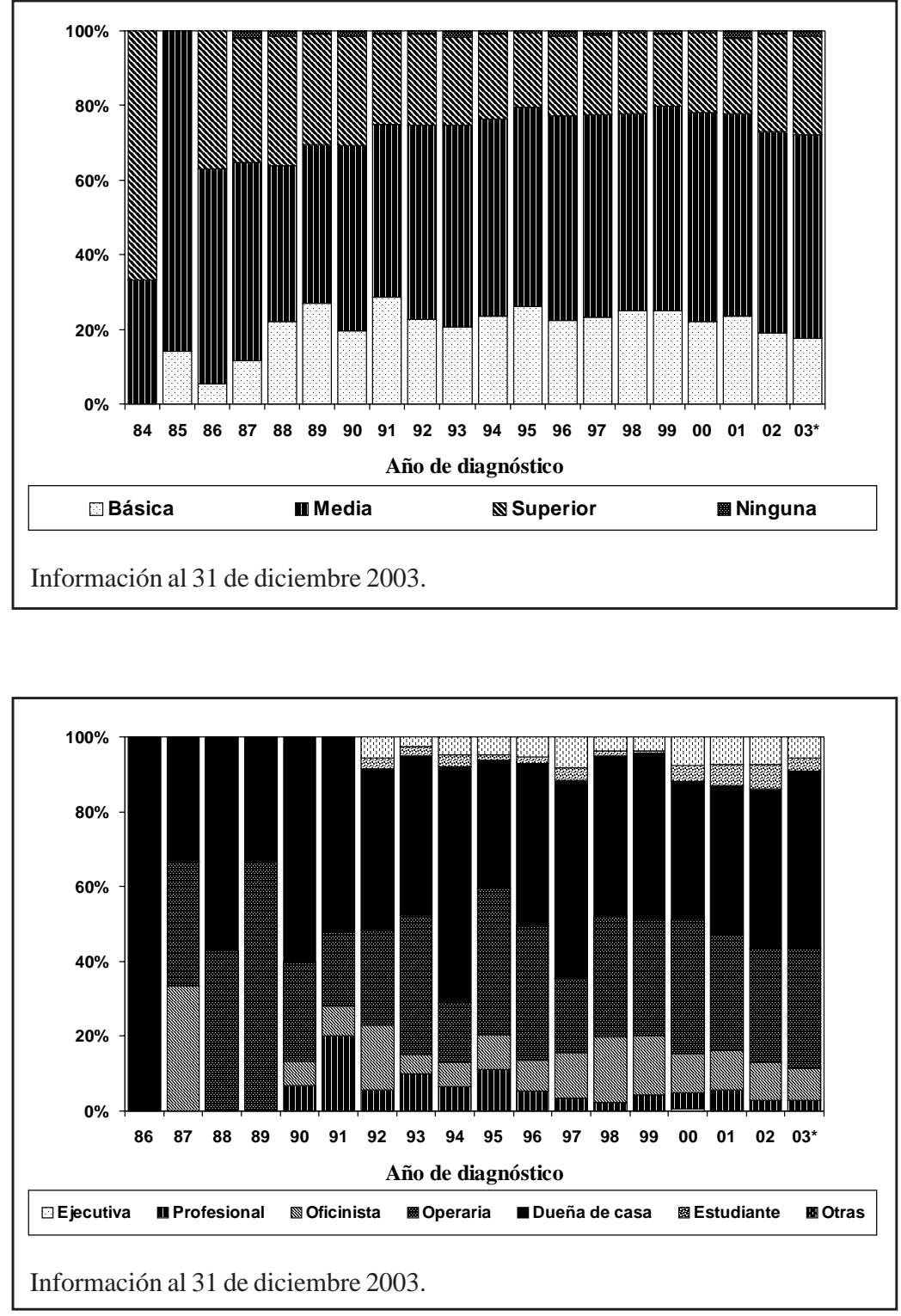

Gráfico 21. Casos de infección por VIH/SIDA y escolaridad en hombres 15 a 49 años. Chile, 1984-2003. Cifra preliminar debido a latencia de la notificación.
Gráfico 22. Casos de infección por VIH/SIDA por ocupación. Mujeres 15 a 49 años. Chile, 1986-2003. Cifra preliminar debido a latencia de la notificación. más notificada. Luego le sigue el nivel Oficinista con un porcentaje para el período acumulado de $21,3 \%$ y la tendencia a través del tiempo a la estabilización de las personas notificadas que declaran este nivel ocupacional (Gráfico 23).

De acuerdo a los resultados anteriores obtenidos en forma acumulada para el período 19842003 se concluye que existe una tendencia al deterioro del nivel de escolaridad tanto en hombres como en mujeres con infección por VIH/ SIDA, afectando mayoritariamente a personas con menor nivel educacional a través del tiempo. Se observa también un deterioro en el nivel ocupacional (en ambos sexos), concordante con lo observado en la escolaridad y reafirmando la tendencia a la pauperización de las personas notificadas.

Tendencia de la edad al diagnóstico de infección por VIH/SIDA: Se evalúa a través del seguimiento en el tiempo de la edad al momento del diagnóstico, se realiza en conjunto para los casos de SIDA (adquisición más antigua) y para los casos asintomáticos por año (adquisición reciente), debido a que el análisis por separado para ambos momentos de la adquisición no muestra diferencias. Los resultados indican que el diagnóstico de infección por VIH/SIDA en mujeres y hombres se realiza mayoritariamente en el grupo etario 25-34 años, siendo esta categoría la más declarada (Gráficos 24 y 25). 


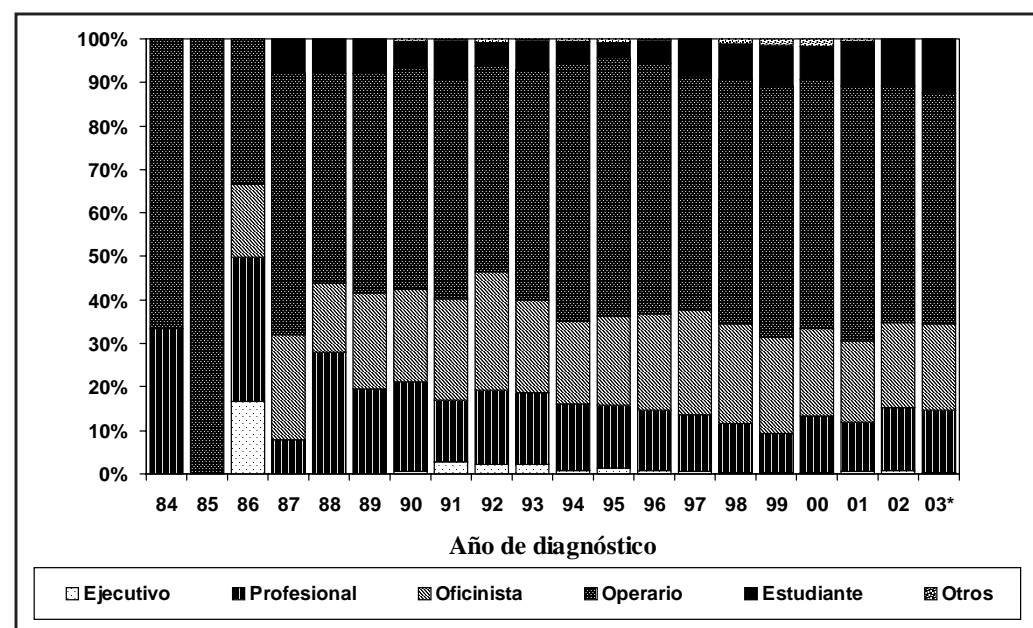

Información al 31 de diciembre 2003.
Gráfico 23. Casos de infección por VIH/SIDA por ocupación. Hombres 15 a 49 años. Chile, 1984-2003. Cifra preliminar debido a latencia de la notificación.

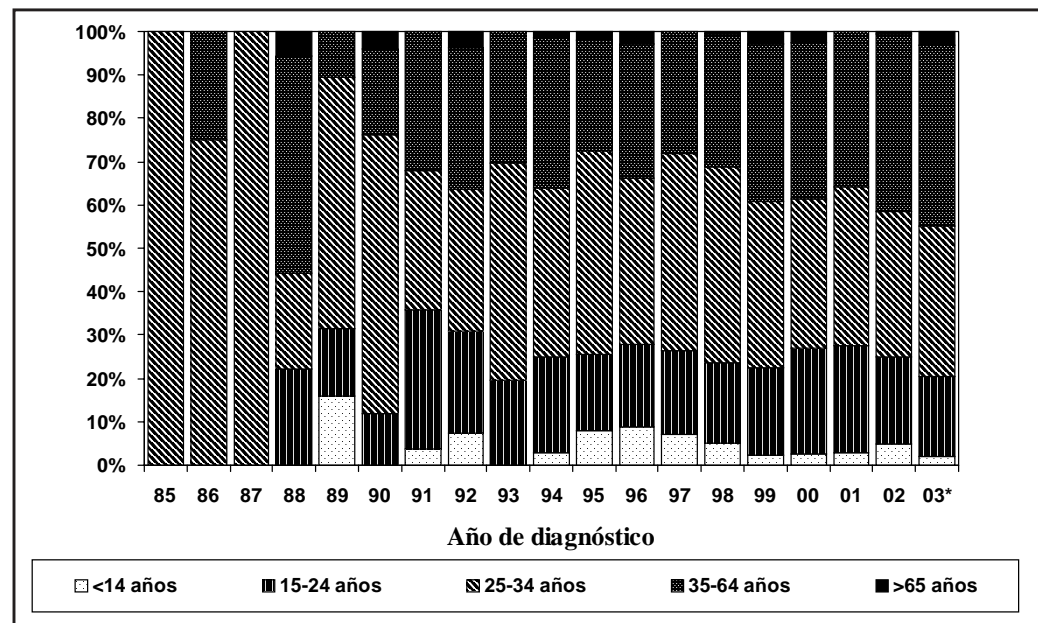

Información al 31 de diciembre 2003.
Gráfico 24. Casos de infección por VIH/SIDA por edad al diagnóstico. Mujeres. Chile, 1985-2003. Cifra preliminar debido a latencia de la notificación.

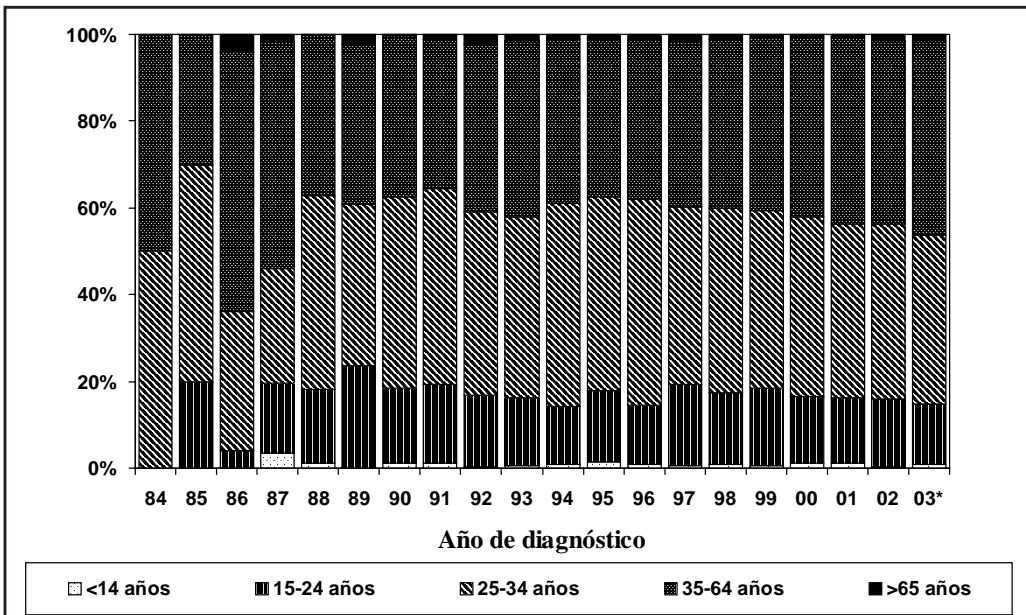

Información al 31 de diciembre 2003.
Gráfico 25. Casos de infección por VIH/SIDA por edad al diagnóstico. Hombres. Chile, 1984-2003. Cifra preliminar debido a latencia de la notificación. 
Dentro de las razones que podrían explicar lo descrito antes está el hecho que los jóvenes en diversos estudios demuestran tener un aumento en las prácticas de autocuidado y por lo tanto, mayor adopción de conductas preventivas, especialmente al ser comparados con la prevención en adultos, representando un impacto de los programas implementados. Otra razón puede atribuirse a la terapias anti-retrovirales que evitan la evolución a SIDA, alargando el período asintomático de la infección y retrasando la aparición de enfermedades marcadoras a edades mayores.

Ruralización: Describe el desplazamiento de los casos hacia localidades rurales. El análisis de los primeros casos notificados en la comuna por año de notificación y según quintil de ruralidad de la comuna de residencia declarada, muestra que la notificación de personas que habitan en zonas rurales comienza a aumentar paulatinamente a través del tiempo y que la epidemia dejó de ser exclusivamente de áreas urbanas. Para el año 2003 destaca y en forma similar al año anterior, la proporción de casos notificados por primera vez en comunas del país que tienen entre 40 y $80 \%$ de población rural. Esto no quiere decir que no se presentaron casos en los otros quintiles, es decir, pueden existir casos pero no corresponden a la primera notificación (Gráfico 26).

Índice de desarrollo humano: En el análisis de las comunas que notificaron se registraron 12.151 casos de infección por VIH/SIDA en 254 comunas, de las cuales 4 no fueron clasificadas por no ser incorporadas en el momento del estudio de IDH. De las 250 comunas con IDH, 213 comunas presentaron menos de 100 casos; 24 comunas entre 100 y 199 casos; 8 comunas entre 200 y 299 casos; 7 comunas entre 300 y 399 casos; 1 comuna entre 600 y 699 casos y 1 comuna sobre 1000 casos de infección por VIH/ SIDA

Según este análisis las comunas que presentaron mayor proporción de casos de infección por VIH/SIDA alcanzan niveles mayores en la clasificación según IDH, es decir, que existe un mayor porcentaje de ampliaciones de las capacidades humanas. Sin embargo, la mayor cantidad de comunas se ubican en niveles bajos de IDH, es así, que 130 comunas tienen IDH entre 0,6 y 0,$69 ; 105$ comunas entre 0,7 y 0,79 y 8 comunas presentan un IDH entre 0,8 y 0,89 y sólo 2 comunas entre 0,9 y 1 de IDH (Tabla 10).

\section{Resumen}

Desde 1984 fecha del primer caso en Chile hasta diciembre 2003 se han notificado, en un sistema de vigilancia pasiva, 6.060 enfermos con SIDA y 6.514 personas con infección por VIH asintomática y sobre 4.000 fallecidos con la infección. Se discute la magnitud de la subnotificación. Las vías de contagio reconocidas son sexual $(94,1 \%)$, sanguínea fundamentalmente drogadicción) 4,3\% y vertical 1,6\%. De acuerdo a los análisis efectuados por Corporación

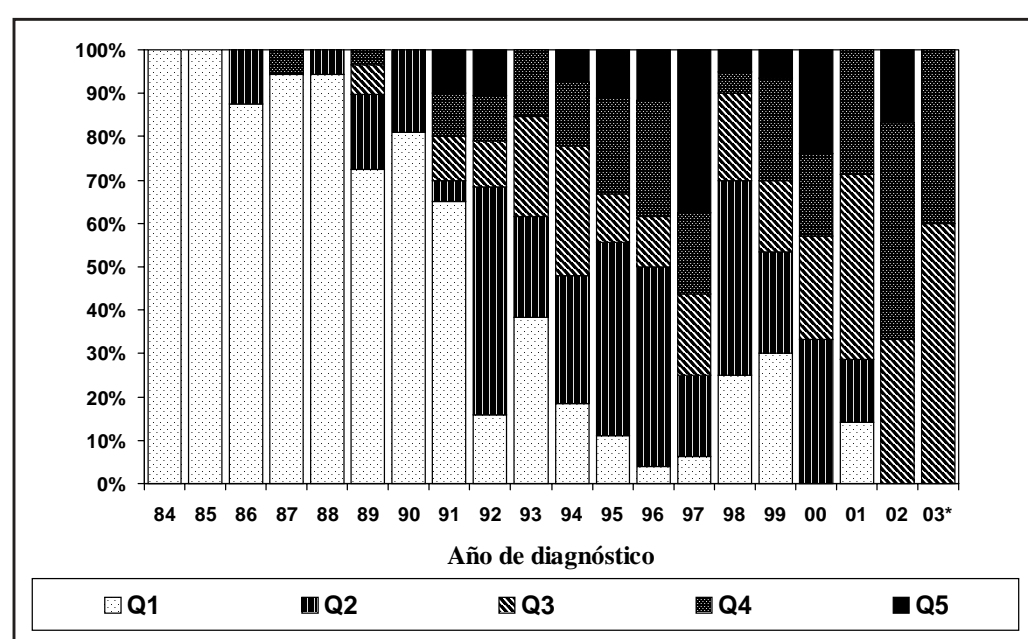

Quintiles definidos de acuerdo a porcentaje de población rural por comunas: Q1 < 20\%; Q2 entre 20 y 40\%; Q3 entre 40 y 60\%; Q4 entre 60 y $80 \%$ y Q5 $>80 \%$

Información al 31 de diciembre 2003.
Gráfico 26. Porcentaje de comunas según quintil de ruralidad por año de diagnóstico del primer caso de infección por VIH/SIDA. Chile. 1984-2003. Cifra preliminar debido a latencia de la notificación. 
Tabla 10. Número de casos de infección por VIH/SIDA en comunas según nivel de logro en el índice de desarrollo humano y porcentaje de ruralidad. Ambos sexos. Chile, 1984-2003*

\begin{tabular}{|c|c|c|c|c|c|}
\hline$n^{0}$ comunas & Comunas & Tasas/100.000 hbtes. & IDH & Ranking IDH & Ruralidad (\%) \\
\hline 1 & Vitacura & 65,51 & 0,924 & 1 & 0,00 \\
\hline 2 & Providencia & 270,73 & 0,904 & 2 & 0,00 \\
\hline 3 & Las Condes & 109,10 & 0,897 & 3 & 0,00 \\
\hline 4 & Lo Barnechea & 61,92 & 0,893 & 4 & 8,00 \\
\hline 5 & La Reina & 76,83 & 0,881 & 5 & 0,00 \\
\hline 6 & Ñuñoa & 184,27 & 0,868 & 6 & 0,00 \\
\hline 7 & Santiago & 519,97 & 0,810 & 11 & 0,00 \\
\hline 8 & Concepción & 68,65 & 0,805 & 12 & 1,20 \\
\hline 9 & San Gregorio & 60,86 & 0,805 & 13 & 100,00 \\
\hline 10 & La Florida & 112,20 & 0,803 & 14 & 0,00 \\
\hline 11 & Viña del Mar & 135,92 & 0,794 & 16 & 0,20 \\
\hline 12 & Temuco & 57,29 & 0,791 & 17 & 13,20 \\
\hline 13 & María Elena & 36,60 & 0,787 & 18 & 1,90 \\
\hline 14 & La Cisterna & 135,15 & 0,787 & 19 & 0,00 \\
\hline 15 & Machalí & 33,12 & 0,782 & 20 & 9,80 \\
\hline 16 & Quilpué & 134,35 & 0,781 & 21 & 53,40 \\
\hline 17 & Macul & 134,14 & 0,777 & 22 & 0,00 \\
\hline 18 & La Serena & 126,64 & 0,776 & 23 & 9,10 \\
\hline 19 & San Miguel & 214,90 & 0,776 & 24 & 0,00 \\
\hline 20 & Maipú & 132,14 & 0,773 & 25 & 1,10 \\
\hline 21 & Pirque & 87,97 & 0,773 & 26 & 47,90 \\
\hline 22 & Sierra Gorda & 70,18 & 0,771 & 27 & 100,00 \\
\hline 23 & Iquique & 131,86 & 0,764 & 28 & 0,70 \\
\hline 24 & San José de Maipo & 77,28 & 0,763 & 29 & 32,00 \\
\hline 25 & Villa Alemana & 101,85 & 0,763 & 30 & 1,40 \\
\hline 26 & Antofagasta & 96,36 & 0,761 & 31 & 0,80 \\
\hline 27 & Santo Domingo & 16,08 & 0,759 & 32 & 66,50 \\
\hline 28 & La Cruz & 18,57 & 0,759 & 33 & 21,70 \\
\hline 29 & Cerrillos & 70,20 & 0,759 & 34 & 0,00 \\
\hline 30 & Punta Arenas & 37,83 & 0,756 & 35 & 45,60 \\
\hline 31 & Coyhaique & 34,64 & 0,756 & 36 & 16,90 \\
\hline 32 & Lo Prado & 117,19 & 0,753 & 37 & 0,00 \\
\hline 33 & Caldera & 33,16 & 0,752 & 38 & 3,00 \\
\hline 34 & Puente Alto & 148,82 & 0,751 & 39 & 14,10 \\
\hline 35 & Diego de Almagro & 21,81 & 0,750 & 40 & 6,40 \\
\hline 36 & Los Andes & 86,44 & 0,749 & 41 & 6,80 \\
\hline 37 & Rancagua & 76,34 & 0,746 & 42 & 86,10 \\
\hline 38 & Peñalolén & 117,92 & 0,746 & 43 & 46,80 \\
\hline 39 & Zapallar & 43,92 & 0,746 & 44 & 24,20 \\
\hline 40 & San Fernando & 12,42 & 0,745 & 45 & 1,80 \\
\hline 41 & Calama & 88,66 & 0,743 & 46 & 4,90 \\
\hline 42 & Arica & 159,33 & 0,743 & 47 & 24,70 \\
\hline 43 & Algarrobo & 67,02 & 0,743 & 48 & 0,00 \\
\hline 44 & San Joaquín & 149,98 & 0,740 & 49 & 0,00 \\
\hline 45 & Estación Central & 158,27 & 0,740 & 50 & 38,90 \\
\hline 46 & Porvenir & 19,59 & 0,738 & 51 & 14,60 \\
\hline
\end{tabular}


Tabla 10. (Continuación)

\begin{tabular}{|c|c|c|c|c|c|}
\hline $\mathrm{n}^{0}$ comunas & Comunas & Tasas/100.000 hbtes. & IDH & Ranking IDH & Ruralidad (\%) \\
\hline 47 & San Felipe & 139,22 & 0,737 & 52 & 0,00 \\
\hline 48 & Recoleta & 181,47 & 0,736 & 53 & 6,60 \\
\hline 49 & Valdivia & 46,66 & 0,735 & 54 & 67,80 \\
\hline 50 & Paine & 34,64 & 0,735 & 55 & 6,00 \\
\hline 51 & Coquimbo & 93,67 & 0,734 & 56 & 31,90 \\
\hline 52 & Castro & 66,82 & 0,734 & 57 & 6,10 \\
\hline 53 & Talca & 94,58 & 0,734 & 58 & 51,40 \\
\hline 54 & Til Til & 38,95 & 0,731 & 59 & 4,60 \\
\hline 55 & San Bernardo & 109,51 & 0,731 & 60 & 13,80 \\
\hline 56 & Mejillones & 110,85 & 0,727 & 61 & 12,10 \\
\hline 57 & Chillán & 55,51 & 0,727 & 62 & 3,00 \\
\hline 58 & Copiapó & 30,72 & 0,726 & 63 & 0,00 \\
\hline 59 & Peñaflor & 55,83 & 0,726 & 64 & 14,70 \\
\hline 60 & Limache & 60,28 & 0,726 & 66 & 0,00 \\
\hline 61 & Conchalí & 205,99 & 0,726 & 67 & 9,40 \\
\hline 62 & Quinta Normal & 152,13 & 0,726 & 68 & 0,00 \\
\hline 63 & La Granja & 104,29 & 0,725 & 69 & 0,00 \\
\hline 64 & Independencia & 200,53 & 0,725 & 70 & 1,00 \\
\hline 65 & Talcahuano & 43,05 & 0,725 & 71 & 1,80 \\
\hline 66 & Tocopilla & 76,05 & 0,725 & 72 & 17,20 \\
\hline 67 & Talagante & 77,94 & 0,725 & 73 & 1,90 \\
\hline 68 & Quillota & 102,97 & 0,724 & 74 & 25,10 \\
\hline 69 & Llay Llay & 29,59 & 0,723 & 75 & 0,20 \\
\hline 70 & Pudahuel & 110,19 & 0,722 & 76 & 51,10 \\
\hline 71 & Calle Larga & 10,14 & 0,722 & 77 & 56,70 \\
\hline 72 & Paihuano & 106,04 & 0,722 & 78 & 0,40 \\
\hline 73 & Valparaíso & 217,79 & 0,721 & 80 & 32,50 \\
\hline 74 & Los Ángeles & 27,75 & 0,720 & 81 & 32,00 \\
\hline 75 & Puerto Montt & 46,16 & 0,720 & 82 & 21,50 \\
\hline 76 & Aysén & 57,62 & 0,719 & 85 & 24,90 \\
\hline 77 & Buin & 41,67 & 0,719 & 86 & 0,00 \\
\hline 78 & El Bosque & 108,18 & 0,719 & 87 & 67,80 \\
\hline 79 & Pedro Aguirre Cerda & 115,76 & 0,719 & 88 & 29,60 \\
\hline 80 & La Ligua & 43,92 & 0,718 & 90 & 4,40 \\
\hline 81 & San Antonio & 117,71 & 0,718 & 91 & 40,20 \\
\hline 82 & Quintero & 84,29 & 0,717 & 93 & 0,00 \\
\hline 83 & Quinta de Tilcoco & 37,10 & 0,717 & 94 & 34,90 \\
\hline 84 & Illapel & 13,79 & 0,717 & 95 & 57,00 \\
\hline 85 & Coinco & 34,35 & 0,717 & 96 & 22,80 \\
\hline 86 & Curicó & 24,97 & 0,716 & 97 & 9,80 \\
\hline 87 & Vallenar & 21,16 & 0,716 & 98 & 38,20 \\
\hline 88 & Curacaví & 36,74 & 0,715 & 99 & 1,30 \\
\hline 89 & Huechuraba & 124,63 & 0,714 & 100 & 6,70 \\
\hline 90 & El Tabo & 88,63 & 0,714 & 101 & 35,90 \\
\hline 91 & Papudo & 25,67 & 0,713 & 102 & 2,90 \\
\hline 92 & Quellón & 6,64 & 0,713 & 103 & 28,20 \\
\hline 93 & Colina & 79,59 & 0,712 & 104 & 65,40 \\
\hline 94 & Quilicura & 165,37 & 0,712 & 105 & 31,40 \\
\hline
\end{tabular}


Tabla 10. (Continuación)

\begin{tabular}{|c|c|c|c|c|c|}
\hline $\mathrm{n}^{\mathbf{0}}$ comunas & Comunas & as/100.000 hbtes. & IDH & Ranking IDH & Ruralidad (\%) \\
\hline 95 & Olmué & 31,74 & 0,712 & 106 & 0,00 \\
\hline 96 & San Ramón & 95,22 & 0,711 & 107 & 13,60 \\
\hline 97 & Cartagena & 226,78 & 0,711 & 108 & 66,10 \\
\hline 98 & Calera de Tango & 50,66 & 0,711 & 109 & 64,40 \\
\hline 99 & Vicuña & 41,55 & 0,708 & 110 & 33,90 \\
\hline 100 & Tierra Amarilla & 42,65 & 0,708 & 111 & 38,00 \\
\hline 101 & Casablanca & 102,47 & 0,707 & 112 & 13,60 \\
\hline 102 & Puerto Natales & 5,79 & 0,706 & 113 & 0,00 \\
\hline 103 & Renca & 113,20 & 0,706 & 114 & 35,00 \\
\hline 104 & Los Vilos & 44,29 & 0,706 & 115 & 2,90 \\
\hline 105 & La Calera & 61,17 & 0,705 & 118 & 7,40 \\
\hline 106 & Panquehue & 50,85 & 0,704 & 119 & 0,00 \\
\hline 107 & La Pintana & 103,16 & 0,704 & 120 & 10,50 \\
\hline 108 & Osorno & 73,57 & 0,704 & 121 & 44,50 \\
\hline 109 & Puchuncaví & 65,66 & 0,702 & 122 & 21,70 \\
\hline 110 & Nogales & 26,78 & 0,702 & 123 & 100,00 \\
\hline 111 & Puerto Varas & 30,16 & 0,702 & 124 & 100,00 \\
\hline 112 & Ovalle & 21,18 & 0,702 & 125 & 36,20 \\
\hline 113 & Melipilla & 26,17 & 0,701 & 126 & 60,80 \\
\hline 114 & San Vicente & 2,84 & 0,700 & 127 & 65,50 \\
\hline 115 & Maullín & 11,69 & 0,700 & 128 & 58,30 \\
\hline 116 & San Esteban & 8,23 & 0,699 & 129 & 71,70 \\
\hline 117 & Pumanque & 53,01 & 0,698 & 130 & 51,30 \\
\hline 118 & Hijuelas & 14,35 & 0,698 & 131 & 75,50 \\
\hline 119 & Placilla & 51,29 & 0,695 & 133 & 0,00 \\
\hline 120 & Cerro Navia & 95,68 & 0,695 & 135 & 20,70 \\
\hline 121 & Huasco & 66,52 & 0,694 & 136 & 23,00 \\
\hline 122 & Linares & 43,98 & 0,694 & 137 & 34,90 \\
\hline 123 & Rengo & 36,68 & 0,694 & 138 & 38,80 \\
\hline 124 & Ancud & 5,33 & 0,693 & 140 & 16,60 \\
\hline 125 & Andacollo & 8,17 & 0,693 & 142 & 32,10 \\
\hline 126 & Olivar & 26,47 & 0,692 & 143 & 8,70 \\
\hline 127 & Pelarco & 26,15 & 0,692 & 144 & 52,80 \\
\hline 128 & Santa María & 43,20 & 0,692 & 145 & 39,60 \\
\hline 129 & Cabildo & 11,42 & 0,691 & 146 & 34,60 \\
\hline 130 & Llanquihue & 48,66 & 0,691 & 147 & 23,00 \\
\hline 131 & San Francisco de Mostazal & 44,11 & 0,690 & 149 & 65,00 \\
\hline 132 & Malloa & 16,32 & 0,689 & 151 & 48,00 \\
\hline 133 & Penco & 24,78 & 0,689 & 152 & 20,80 \\
\hline 134 & Graneros & 48,99 & 0,688 & 154 & 41,20 \\
\hline 135 & Yungay & 26,16 & 0,688 & 155 & 32,90 \\
\hline 136 & Isla de Maipo & 29,49 & 0,687 & 156 & 65,30 \\
\hline 137 & Villa Alegre & 13,20 & 0,687 & 157 & 6,00 \\
\hline 138 & El Quisco & 82,01 & 0,686 & 159 & 40,00 \\
\hline 139 & La Unión & 5,16 & 0,686 & 160 & 0,00 \\
\hline 140 & Lo Espejo & 123,26 & 0,685 & 161 & 22,40 \\
\hline 141 & Doñihue & 6,86 & 0,685 & 163 & 46,40 \\
\hline 142 & Catemu & 8,85 & 0,685 & 164 & 15,70 \\
\hline
\end{tabular}


Tabla 10. (Continuación)

\begin{tabular}{|c|c|c|c|c|c|}
\hline $\mathrm{n}^{0}$ comunas & Comunas & asas/100.000 hbtes. & IDH & Ranking IDH & Ruralidad (\%) \\
\hline 143 & Taltal & 36,86 & 0,684 & 168 & 74,00 \\
\hline 144 & Peumo & 7,79 & 0,684 & 170 & 88,00 \\
\hline 145 & Coltauco & 19,73 & 0,681 & 171 & 29,80 \\
\hline 146 & Curacautín & 22,06 & 0,680 & 172 & 35,20 \\
\hline 147 & Lampa & 27,96 & 0,680 & 173 & 100,00 \\
\hline 148 & San Pedro & 88,94 & 0,679 & 175 & 4,50 \\
\hline 149 & Coronel & 50,34 & 0,679 & 176 & 79,00 \\
\hline 150 & Pitrufquén & 14,98 & 0,679 & 178 & 36,70 \\
\hline 151 & Villarrica & 52,97 & 0,679 & 179 & 60,30 \\
\hline 152 & Río Negro & 31,20 & 0,678 & 180 & 39,10 \\
\hline 153 & Freirina & 57,46 & 0,677 & 182 & 38,10 \\
\hline 154 & Corral & 52,04 & 0,677 & 183 & 65,30 \\
\hline 155 & Las Cabras & 22,55 & 0,676 & 184 & 70,70 \\
\hline 156 & Dalcahue & 12,88 & 0,676 & 185 & 55,00 \\
\hline 157 & Requínoa & 20,58 & 0,675 & 186 & 74,40 \\
\hline 158 & San Pablo & 26,84 & 0,675 & 187 & 18,40 \\
\hline 159 & El Monte & 68,55 & 0,675 & 188 & 73,20 \\
\hline 160 & Colbún & 17,70 & 0,672 & 194 & 40,60 \\
\hline 161 & Loncoche & 33,84 & 0,671 & 196 & 71,90 \\
\hline 162 & Marchigue & 16,11 & 0,670 & 199 & 35,50 \\
\hline 163 & Pichidegua & 12,05 & 0,670 & 200 & 3,30 \\
\hline 164 & Pucón & 13,93 & 0,667 & 205 & 46,10 \\
\hline 165 & Santa Cruz & 23,93 & 0,667 & 207 & 100,00 \\
\hline 166 & San Pedro de Atacama & 106,04 & 0,667 & 209 & 45,40 \\
\hline 167 & San Carlos & 20,78 & 0,667 & 210 & 66,10 \\
\hline 168 & Combarbalá & 13,91 & 0,666 & 212 & 32,00 \\
\hline 169 & Cauquenes & 22,34 & 0,666 & 213 & 100,00 \\
\hline 170 & Camiña & 70,32 & 0,665 & 216 & 15,40 \\
\hline 171 & Tomé & 22,32 & 0,664 & 217 & 39,70 \\
\hline 172 & Chile Chico & 26,62 & 0,664 & 218 & 52,00 \\
\hline 173 & Bulnes & 35,51 & 0,663 & 219 & 42,80 \\
\hline 174 & Arauco & 37,09 & 0,663 & 220 & 28,20 \\
\hline 175 & Laja & 49,28 & 0,663 & 221 & 78,70 \\
\hline 176 & Romeral & 8,70 & 0,663 & 222 & 41,60 \\
\hline 177 & Lautaro & 10,44 & 0,662 & 223 & 0,00 \\
\hline 178 & Pozo Almonte & 63,27 & 0,661 & 224 & 4,10 \\
\hline 179 & Punitaqui & 11,46 & 0,660 & 227 & 15,10 \\
\hline 180 & Angol & 6,49 & 0,659 & 228 & 0,30 \\
\hline 181 & Lota & 31,84 & 0,659 & 229 & 77,70 \\
\hline 182 & Teno & 4,15 & 0,659 & 230 & 63,30 \\
\hline 183 & Cunco & 10,91 & 0,658 & 231 & 52,90 \\
\hline 184 & Purranque & 9,91 & 0,657 & 232 & 31,50 \\
\hline 185 & Molina & 25,23 & 0,656 & 233 & 90,70 \\
\hline 186 & Ñiquén & 7,60 & 0,656 & 234 & 60,50 \\
\hline 187 & Fresia & 30,74 & 0,655 & 237 & 8,20 \\
\hline 188 & Curanilahue & 80,28 & 0,655 & 238 & 80,50 \\
\hline 189 & Río Claro & 23,83 & 0,653 & 240 & 22,70 \\
\hline 190 & Constitución & 9,92 & 0,651 & 242 & 85,00 \\
\hline
\end{tabular}


Tabla 10. (Continuación)

\begin{tabular}{|c|c|c|c|c|c|}
\hline $\mathrm{n}^{\mathbf{0}}$ comunas & Comunas & Tasas/100.000 hbtes. & IDH & Ranking IDH & Ruralidad (\%) \\
\hline 191 & San Ignacio & 30,30 & 0,651 & 243 & 46,30 \\
\hline 192 & Cañete & 13,64 & 0,650 & 244 & 90,60 \\
\hline 193 & San Juan de la Costa & 30,68 & 0,650 & 245 & 76,30 \\
\hline 194 & Pichilemu & 9,51 & 0,649 & 246 & 65,70 \\
\hline 195 & Ercilla & 56,55 & 0,647 & 249 & 53,20 \\
\hline 196 & Negrete & 11,98 & 0,647 & 250 & 37,90 \\
\hline 197 & Hualqui & 6,19 & 0,646 & 251 & 73,80 \\
\hline 198 & Sagrada Familia & 11,84 & 0,646 & 252 & 80,20 \\
\hline 199 & Longaví & 14,28 & 0,646 & 253 & 59,30 \\
\hline 200 & Hualañé & 258,12 & 0,646 & 254 & 34,30 \\
\hline 201 & Victoria & 39,42 & 0,646 & 255 & 59,80 \\
\hline 202 & Río Bueno & 18,19 & 0,645 & 256 & 67,00 \\
\hline 203 & Monte Patria & 7,05 & 0,645 & 257 & 100,00 \\
\hline 204 & Vichuquén & 81,12 & 0,645 & 259 & 80,60 \\
\hline 205 & Maule & 43,58 & 0,644 & 260 & 68,50 \\
\hline 206 & Futrono & 7,12 & 0,642 & 262 & 36,50 \\
\hline 207 & Collipulli & 17,57 & 0,642 & 263 & 100,00 \\
\hline 208 & La Higuera & 28,59 & 0,641 & 264 & 72,50 \\
\hline 209 & San Nicolás & 10,53 & 0,640 & 265 & 49,90 \\
\hline 210 & Putaendo & 39,04 & 0,640 & 266 & 59,10 \\
\hline 211 & Chanco & 10,54 & 0,640 & 267 & 4,00 \\
\hline 212 & Quirihue & 18,23 & 0,639 & 268 & 68,10 \\
\hline 213 & Rauco & 25,57 & 0,637 & 269 & 59,90 \\
\hline 214 & Los Lagos & 5,39 & 0,636 & 272 & 33,00 \\
\hline 215 & Traiguén & 19,40 & 0,635 & 275 & 28,00 \\
\hline 216 & Nacimiento & 26,93 & 0,635 & 276 & 43,40 \\
\hline 217 & Coelemu & 24,05 & 0,634 & 277 & 0,00 \\
\hline 218 & Parral & 10,51 & 0,634 & 278 & 57,00 \\
\hline 219 & Curarrehue & 16,73 & 0,633 & 279 & 70,60 \\
\hline 220 & San Clemente & 41,19 & 0,633 & 280 & 44,70 \\
\hline 221 & Gorbea & 34,13 & 0,632 & 281 & 62,60 \\
\hline 222 & Antuco & 49,24 & 0,632 & 283 & 80,30 \\
\hline 223 & Lago Ranco & 28,68 & 0,632 & 284 & 76,70 \\
\hline 224 & Curepto & 24,42 & 0,632 & 285 & 61,40 \\
\hline 225 & Chimbarongo & 3,26 & 0,630 & 286 & 49,90 \\
\hline 226 & San Javier & 39,34 & 0,630 & 288 & 19,50 \\
\hline 227 & Lebú & 36,37 & 0,629 & 289 & 34,40 \\
\hline 228 & Mulchén & 6,68 & 0,628 & 291 & 56,00 \\
\hline 229 & Santa Juana & 16,73 & 0,624 & 294 & 47,10 \\
\hline 230 & Paillaco & 11,02 & 0,622 & 297 & 81,00 \\
\hline 231 & Toltén & 33,16 & 0,622 & 298 & 14,80 \\
\hline 232 & Quillón & 6,87 & 0,620 & 300 & 41,90 \\
\hline 233 & Purén & 21,56 & 0,619 & 301 & 67,60 \\
\hline 234 & Quilleco & 19,06 & 0,618 & 302 & 70,80 \\
\hline 235 & Florida & 19,16 & 0,618 & 304 & 66,50 \\
\hline 236 & Lonquimay & 10,99 & 0,618 & 305 & 36,20 \\
\hline 237 & Cabrero & 18,43 & 0,618 & 308 & 76,90 \\
\hline 238 & Galvarino & 7,10 & 0,612 & 309 & 74,80 \\
\hline
\end{tabular}


Tabla 10. (Continuación)

\begin{tabular}{clcccc}
\hline $\mathbf{n}^{\mathbf{0}}$ comunas & Comunas & Tasas/100.000 hbtes. & IDH & Ranking IDH & Ruralidad (\%) \\
\hline 239 & El Carmen & 7,06 & 0,612 & 310 & 78,40 \\
240 & Freire & 13,05 & 0,611 & 312 & 45,20 \\
241 & Renaico & 10,87 & 0,609 & 315 & 76,10 \\
242 & Coihueco & 13,28 & 0,608 & 317 & 83,70 \\
243 & Puerto Saavedra & 6,93 & 0,607 & 318 & 58,30 \\
244 & Panguipulli & 33,15 & 0,605 & 319 & 59,20 \\
245 & Nueva Imperial & 18,98 & 0,605 & 320 & 61,10 \\
246 & Carahue & 27,45 & 0,599 & 321 & 2,00 \\
247 & Pencahue & 25,46 & 0,597 & 324 & 20,50 \\
248 & Portezuelo & 33,50 & 0,595 & 325 & 65,50 \\
249 & Vilcún & 4,79 & 0,583 & 329 & 54,50 \\
250 & Yumbel & 19,55 & 0,565 & 333 & 0,30 \\
251 & Chiguayante & 24,84 & S/I & & 3,00 \\
252 & Concón & 52,99 & S/I & & 3,00 \\
253 & Isla de Pascua & 72,36 & S/I & & 33,50 \\
254 & San Pedro de la Paz & 16,22 & S/I & & 1,20 \\
\hline
\end{tabular}

Nacional de SIDA-CONASIDA, organismo gubernamental, la infección por VIH/SIDA se caracteriza en Chile por: predominio en hombres homo/bisexuales, su localización urbana y rural, pauperización de los afectados tanto mujeres como hombres, diagnosticarse mayoritariamente en la edad adulta, una tendencia estable a la feminización de la epidemia y a una distribución heterosexual. Desde el año 2001 se ha ampliado en forma paulatina el acceso para los beneficiarios de la salud pública a triterapia anti retroviral alcanzando a $100 \%$ de cobertura y gratuidad desde el año 2003, con lo cual ha disminuido ostensiblemente la frecuencia de manifestaciones de SIDA mientras la mortalidad cayó significativamente desde 15,5\% (período 1993-1997) a $0,2 \%$ (período 1998-2003).

\section{Bibliografía}

1.- Boletín Epidemiológico semestral de CONASIDA $\mathrm{N}^{\circ}$ 12. Junio 2000. Serie de Documentos CONASIDA, Ministerio de Salud.

2.- ONUSIDA, 2002. Resumen mundial de la epidemia de VIH/SIDA.

3.- Ministerio de Salud de Chile. Determinación del virus del SIDA en Bancos de sangre. Ordinario No 4018, 14 de Julio 1987.

4.- ONUSIDA, 2003. Situación de la epidemia de SIDA.

5.- Villarroel del Pino L. Futuro de las epidemias de VIH/ SIDA: una proyección para Chile. Tesis para optar al grado de Magíster en Estadística. Dpto. Estadística. Universidad Católica de Chile. 1997.

Correspondencia a:

Anabella Arredondo

CONASIDA

conasida@minsal.cl 